\title{
Stereochemistries and biological properties of Oligomycin A Diels-Alder adducts
}

Olga A. Omelchuk ${ }^{1}$, Vadim I. Malyshev ${ }^{2}$, Michael G. Medvedev ${ }^{2,3^{*}}$, Lyudmila N. Lysenkova ${ }^{1}$, Nikita M. Belov ${ }^{1}$, Lyubov G. Dezhenkova ${ }^{1}$, Natalia E. Grammatikova ${ }^{1}$, Alexander M. Scherbakov $^{4}$, Andrey E. Shchekotikhin ${ }^{1,5 \#}$

${ }^{1}$ Gause Institute of New Antibiotics, Moscow, 119021, Russian Federation.

${ }^{2}$ N. D. Zelinsky Institute of Organic Chemistry, Russian Academy of Sciences, Leninsky Prospect 47, Moscow, 119991, Russian Federation

${ }^{3}$ National Research University Higher School of Economics, Myasnitskaya Street 20, 101000, Moscow, Russian Federation.

${ }^{4}$ Department of Experimental Tumor Biology, N.N. Blokhin National Medical Research Center of Oncology, Moscow, Russian Federation

${ }^{5}$ D. I. Mendeleev University of Chemical Technology of Russia, Moscow, 125047, Russian Federation.

Corresponding authors:

*E-mail: medvedev.m.g@gmail.com

\#E-mail: shchekotikhin@mail.ru

\section{SUPPORTING INFORMATION}

\section{Table of Contents}

Characterization SI-3

Figure S1 HRMS-ESI of the benzoquinone adduct of oligomycin A endo- $2 b$. SI-3

Figure S2 IR spectra of the benzoquinone adduct of oligomycin A endo-2b. SI-4

Figure S3 HPLC of the benzoquinone adduct of oligomycin A endo-2b. SI-5

Figure S4 HRMS-ESI of the $N$-benzylmaleimide adduct of oligomycin A endo-3a. SI-6

Figure S5 IR spectra of the $N$-benzylmaleimide adduct of oligomycin A endo-3a. SI-7

Figure S6 HPLC of the $N$-benzylmaleimide adduct of oligomycin A endo-3a. SI-8

Figure S7 HRMS-ESI of the $N$-benzylmaleimide adduct of oligomycin A exo-3b. SI-9

Figure S8 IR spectra of the $N$-benzylmaleimide adduct of oligomycin A exo-3b. SI-10

Figure S9 HPLC of the $N$-benzylmaleimide adduct of oligomycin A exo-3b. SI-11

Figure $\mathrm{S} 10{ }^{1} \mathrm{H}$ NMR spectra of the benzoquinone adduct endo- $2 \mathrm{~b}\left(600 \mathrm{MHz}, \mathrm{CD}_{3} \mathrm{OD}\right)$. SI-12

Figure $\mathrm{S} 11{ }^{13} \mathrm{C}$ NMR spectra of the benzoquinone adduct endo-2b (150 MHz, $\left.\mathrm{CD}_{3} \mathrm{OD}\right)$. SI-13

Figure $\mathrm{S} 12{ }^{1} \mathrm{H}_{-}{ }^{13} \mathrm{C}$ HSQC NMR spectrum of the benzoquinone adduct endo- $2 \mathrm{~b}\left(\mathrm{CD}_{3} \mathrm{OD}\right)$ SI-14

Figure $\mathrm{S} 13{ }^{1} \mathrm{H}^{13} \mathrm{C}$ HMBC NMR spectrum of the benzoquinone adduct endo- $2 \mathrm{~b}\left(\mathrm{CD}_{3} \mathrm{OD}\right)$ SI-15

Figure $\mathrm{S} 14{ }^{1} \mathrm{H}-{ }^{1} \mathrm{H}$ COSY NMR spectrum of the benzoquinone adduct endo-2b $\left(\mathrm{CD}_{3} \mathrm{OD}\right)$. SI-16

Figure $\mathrm{S} 15{ }^{1} \mathrm{H}-{ }^{1} \mathrm{H}$ ROESY NMR spectrum of the benzoquinone adduct endo- $2 \mathrm{~b}\left(\mathrm{CD}_{3} \mathrm{OD}\right)$. SI-17

Figure $\mathrm{S} 16{ }^{1} \mathrm{H}$ NMR spectrum of the N-benzylmaleimide adduct endo-3a (600 MHz, CD3OD).....SI-18 Figure $\mathrm{S} 17{ }^{13} \mathrm{C}$ NMR spectrum of the $N$-benzylmaleimide adduct endo-3a (150 MHz, CD $\left.{ }_{3} \mathrm{OD}\right) \ldots . . \mathrm{SI}-19$ Figure $\mathrm{S} 18{ }^{1} \mathrm{H}_{-}{ }^{13} \mathrm{C}$ HSQC NMR spectrum of the $N$-benzylmaleimide adduct endo-3a $\left(\mathrm{CD}_{3} \mathrm{OD}\right) \ldots . . \mathrm{SI}-20$ Figure $\mathrm{S} 19{ }^{1} \mathrm{H}_{-}{ }^{13} \mathrm{C}$ HMBC NMR spectrum of the $N$-benzylmaleimide adduct endo-3a $\left(\mathrm{CD}_{3} \mathrm{OD}\right) \ldots \mathrm{SI}-21$ Figure $\mathrm{S} 20{ }^{1} \mathrm{H}-{ }^{1} \mathrm{H}$ COSY NMR spectrum of the $N$-benzylmaleimide adduct endo- $3 \mathrm{a}\left(\mathrm{CD}_{3} \mathrm{OD}\right) \ldots . . . \mathrm{SI}-22$ 
Figure $\mathrm{S} 21{ }^{1} \mathrm{H}-{ }^{1} \mathrm{H}$ ROESY NMR spectrum of the $N$-benzylmaleimide adduct endo- $3 \mathrm{a}\left(\mathrm{CD}_{3} \mathrm{OD}\right)$. ..SI-23

Figure $\mathrm{S} 22{ }^{1} \mathrm{H}$ NMR spectrum of the $N$-benzylmaleimide adduct exo-3b (600 MHz, $\left.\mathrm{CD}_{3} \mathrm{OD}\right)$........ SI-24

Figure $\mathrm{S} 23{ }^{13} \mathrm{C}$ NMR spectrum of the $N$-benzylmaleimide adduct exo-3b (150 MHz, $\left.\mathrm{CD}_{3} \mathrm{OD}\right)$....... SI-25

Figure $\mathrm{S} 24{ }^{1} \mathrm{H}^{13} \mathrm{C}$ HSQC NMR spectrum of the $N$-benzylmaleimide adduct exo-3b $\left(\mathrm{CD}_{3} \mathrm{OD}\right) \ldots \ldots . . \mathrm{SI}-26$

Figure $\mathrm{S} 25{ }^{1} \mathrm{H}^{13} \mathrm{C}$ HMBC NMR spectrum of the $N$-benzylmaleimide adduct exo-3b $\left(\mathrm{CD}_{3} \mathrm{OD}\right) \ldots . . . \mathrm{SI}-27$

Figure $\mathrm{S} 26{ }^{1} \mathrm{H}-{ }^{1} \mathrm{H}$ COSY NMR spectrum of the $N$-benzylmaleimide adduct exo-3b $\left(\mathrm{CD}_{3} \mathrm{OD}\right) \ldots \ldots . . . \mathrm{SI}-28$

Figure $\mathrm{S} 27{ }^{1} \mathrm{H}-{ }^{1} \mathrm{H}$ ROESY NMR spectrum of the cis-exo $N$-benzylmaleimide adduct exo-3b $\left(\mathrm{CD}_{3} \mathrm{OD}\right)$.

Geometries optimization and calculation of the free energies of s-cis and s-trans oligomycin conformations

Search for transition states of Diels-Alder reactions with benzoquinone

Search for transition states of Diels-Alder reactions with N-benzylmaleimide. SI-31

Conformational search for products of Oligomycin A Diels-Alder reactions SI-33 


\section{Characterization}

\section{Compound Spectrum List Report}

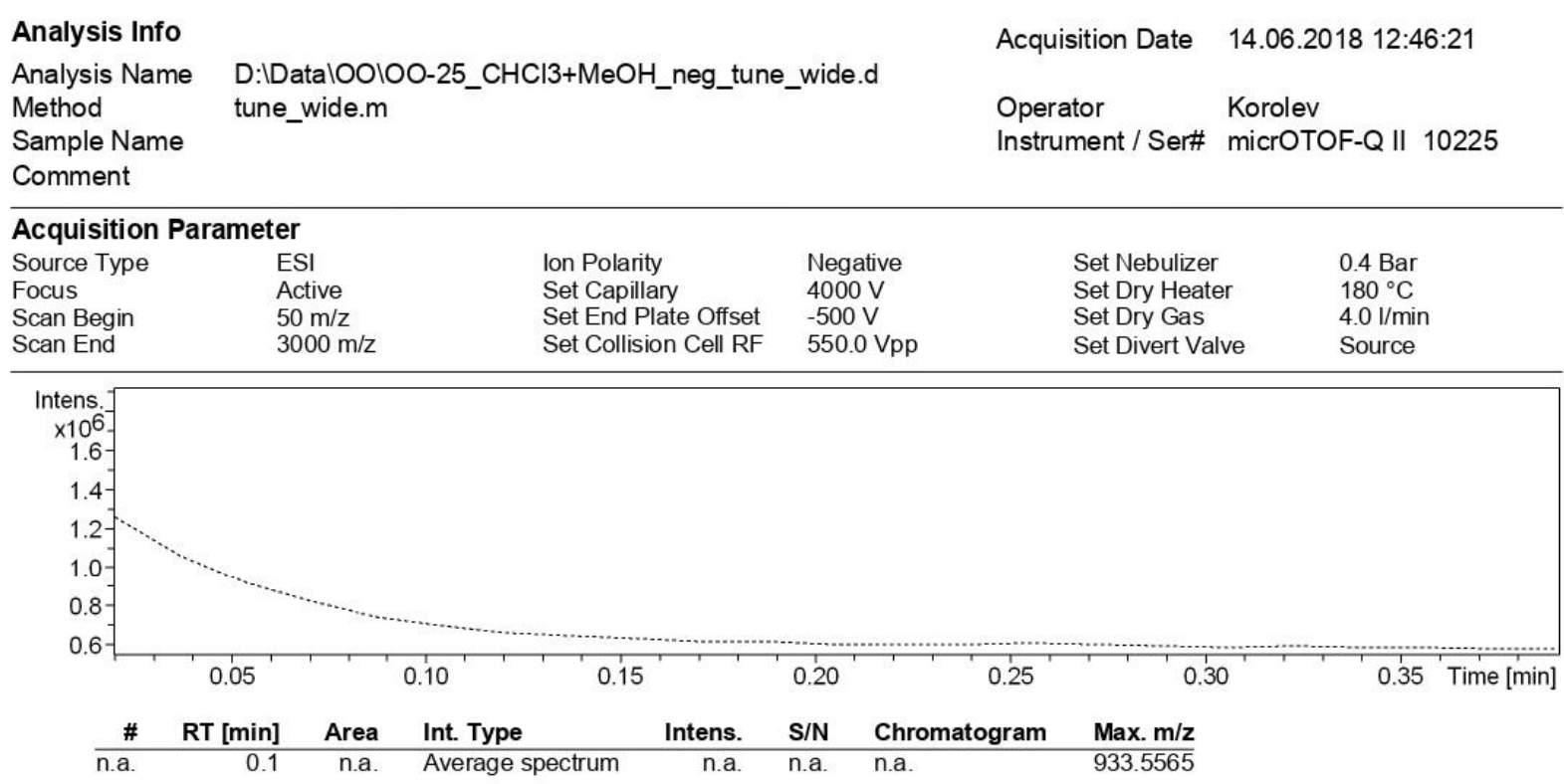

-MS, 0.1-0.2min \#(3-10)

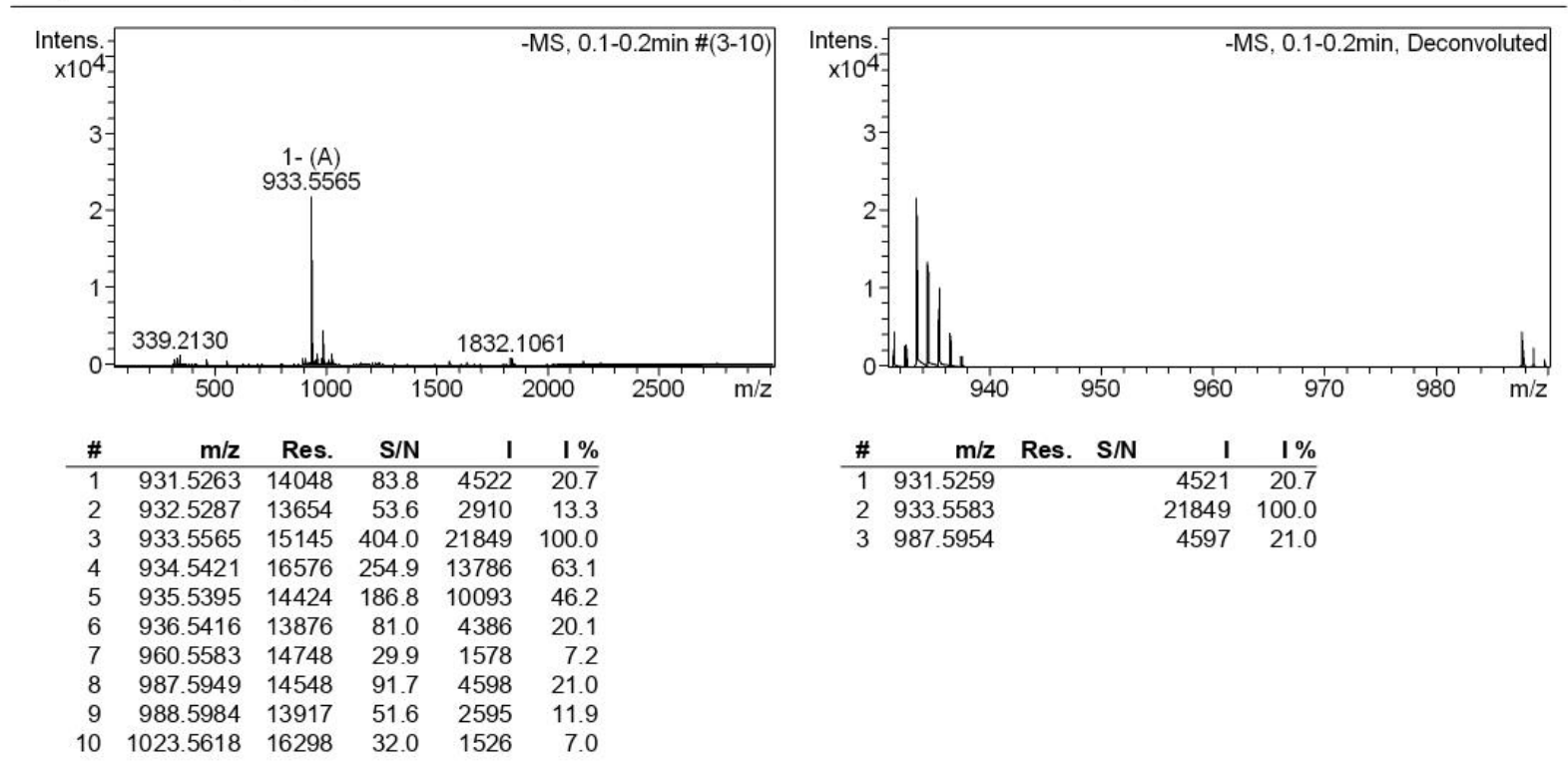

Figure S1 HRMS-ESI of the benzoquinone adduct of oligomycin A endo-2b. 


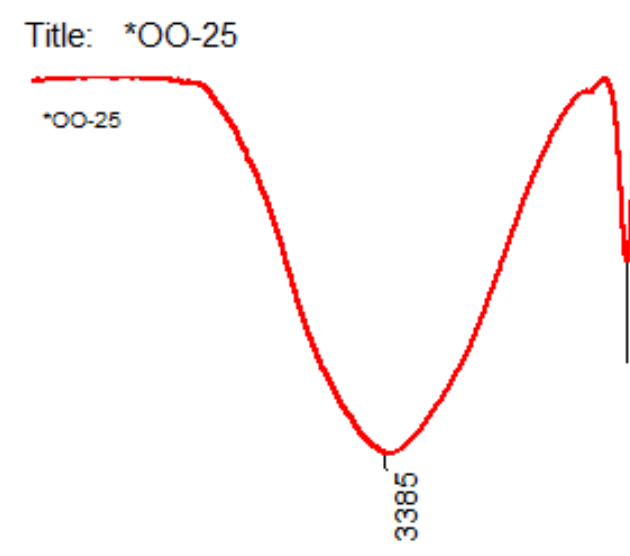

21 Mar 2019 06:12:49

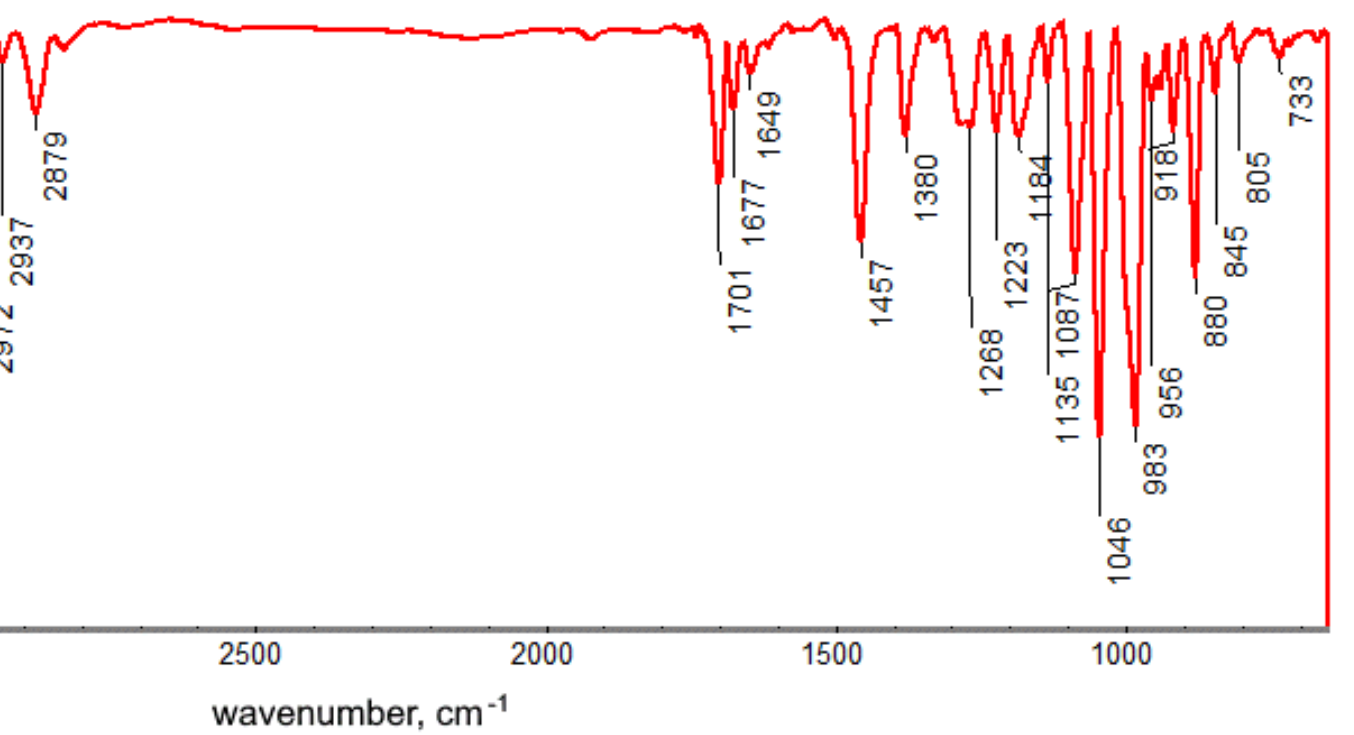

Expanded fingerprint region:

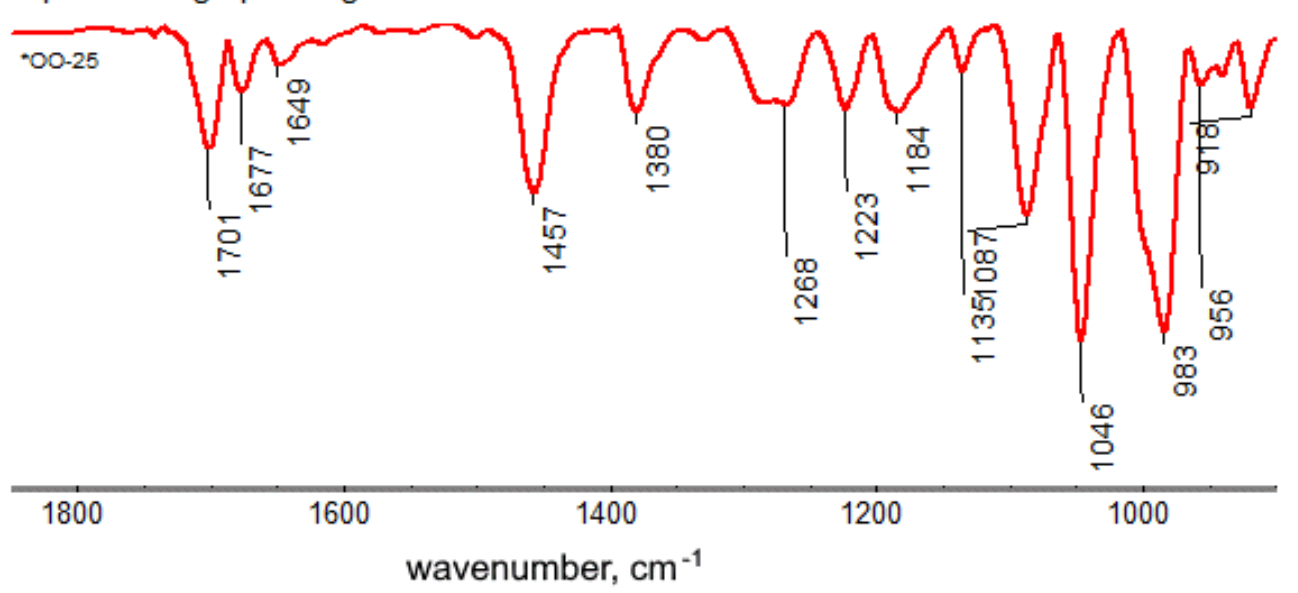

Acquisition Date 21.03.2019 06:03:05

The number of sample scans: 64

The number of reference scans: 64

The resolution: 4.000

The amplification: 8.0

The mirror motion speed: 0.4747

The diaphragm: 150.00

Figure S2 IR spectra of the benzoquinone adduct of oligomycin A endo-2b. 
Chromatogram

OO-25_3 C:ILabSolutions\DatalOlygolOO O0412-02.lcd

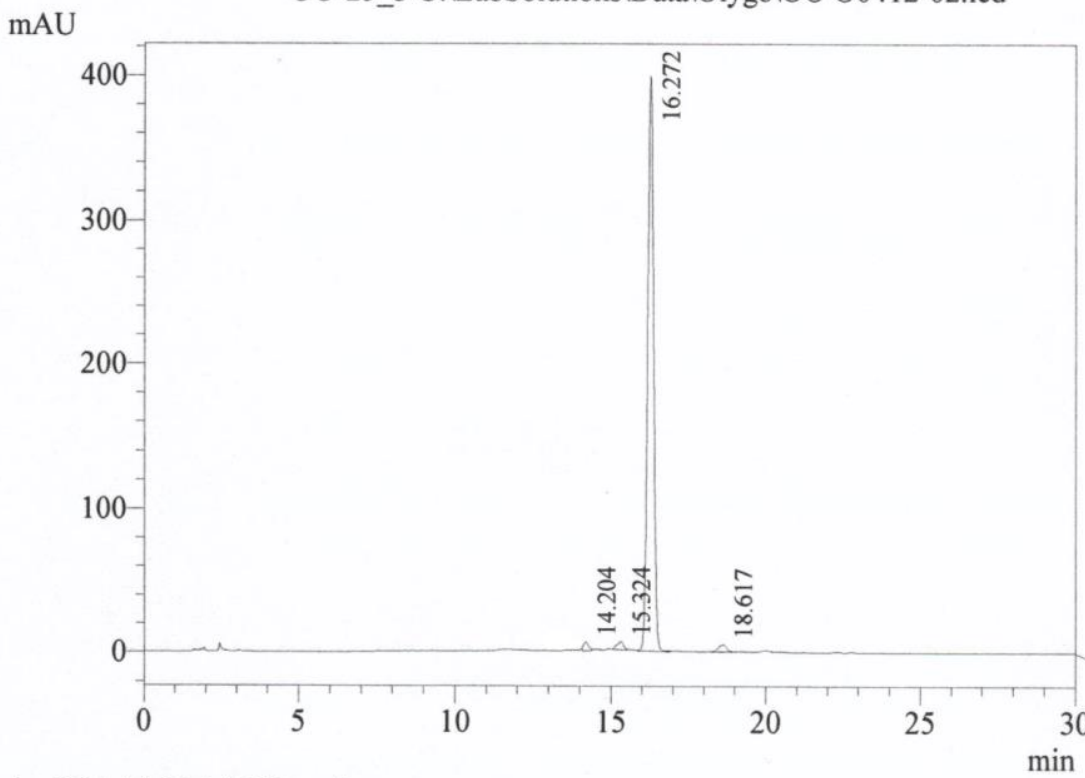

1PDA Multi 1

1 PDA Multi $1 / 230 \mathrm{~nm} 4 \mathrm{~nm}$

PDA Ch1 230nm 4nm

PeakTable

\begin{tabular}{|r|r|r|r|r|}
\hline Peak\# & Ret. Time & \multicolumn{1}{|c|}{ Area } & Height & \multicolumn{1}{c|}{ Area \% } \\
\hline 1 & 14.204 & 58225 & 5604 & 1.061 \\
\hline 2 & 15.324 & 70625 & 5164 & 1.287 \\
\hline 3 & 16.272 & 5278162 & 398149 & 96.178 \\
\hline 4 & 18.617 & 80922 & 4806 & 1.475 \\
\hline Total & & 5487934 & 413722 & 100.000 \\
\hline
\end{tabular}

$<<$ LC Program $>>$

Time

0.10

10.00

30.00

33.00

45.00

Method

$\begin{array}{lll}\text { Unit } & \text { Command } & \text { Value } \\ \text { Pumps } & \text { B.Conc } & 70 \\ \text { Pumps } & \text { B.Conc } & 85 \\ \text { Pumps } & \text { B.Conc } & 85 \\ \text { Pumps } & \text { B.Conc } & 70 \\ \text { Controller } & \text { Stop } & \end{array}$

Sample Information

Method Filename : WAT Oligo.lcm

Date Acquired $\quad: 12.04 .2019$

Shimadzu LC-20AD; 2-System FRA, Colon Kromasil 100-C18,.size 5mkm, 4,6*250mm, N 58403 Elution: A - H2O : B - MeCN, fl. 1,0 ml/min, loop $20 \mathrm{mkl}$.

Figure S3 HPLC of the benzoquinone adduct of oligomycin A endo-2b. 


\section{Compound Spectrum List Report}

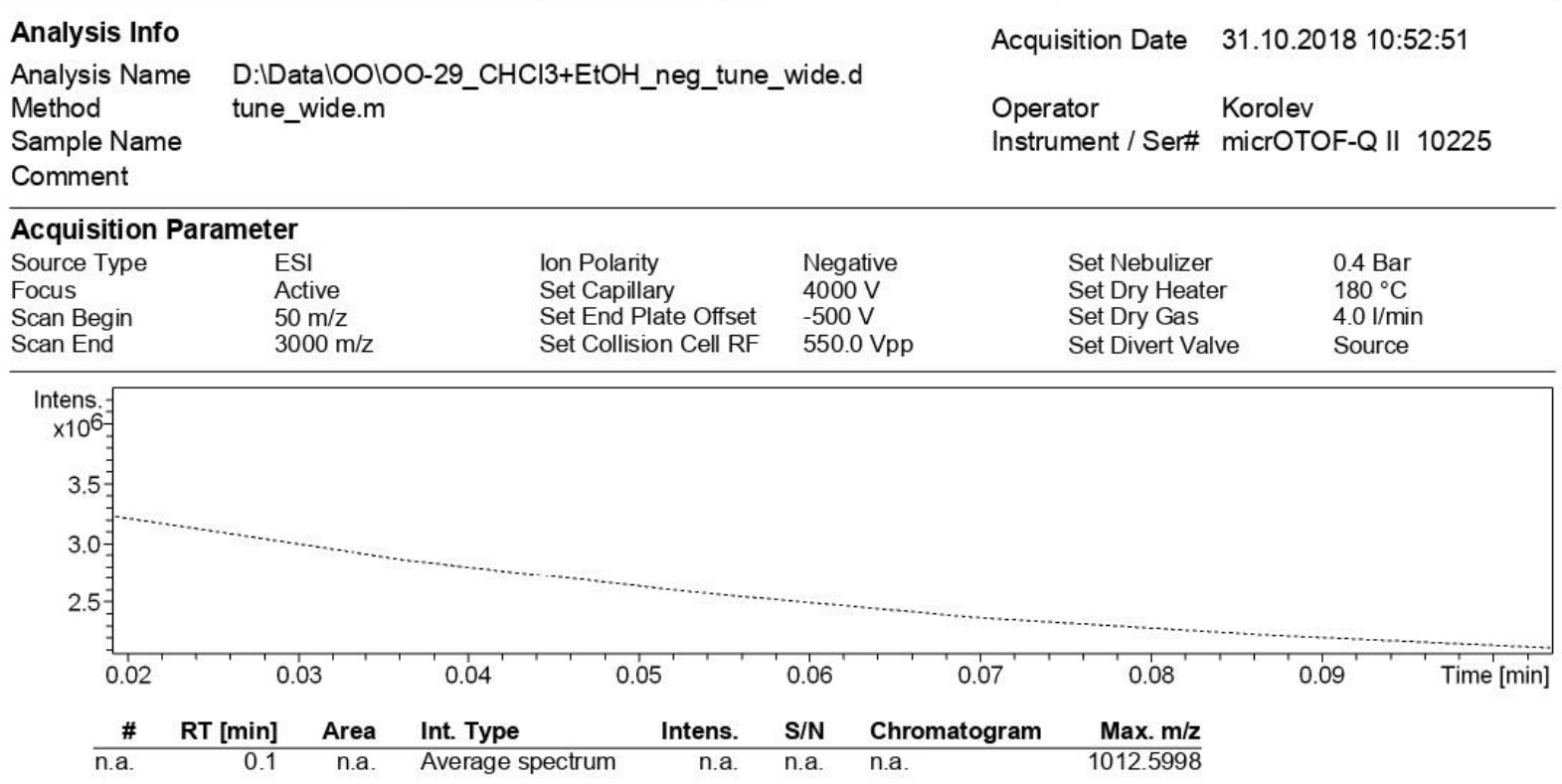

-MS, 0.0-0.1 min \#(2-4)

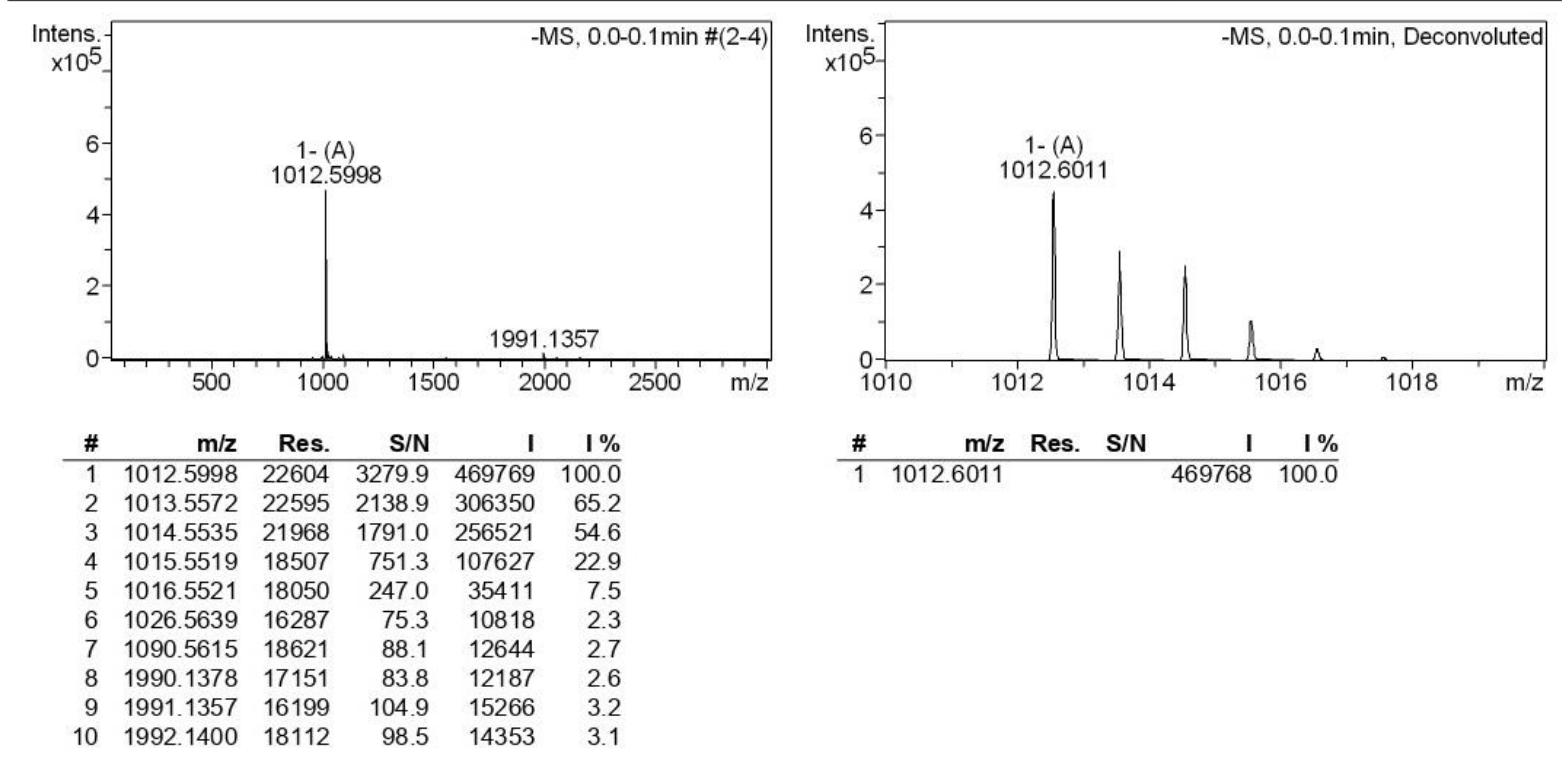

Figure S4 HRMS-ESI of the $N$-benzylmaleimide adduct of oligomycin A endo-3a. 

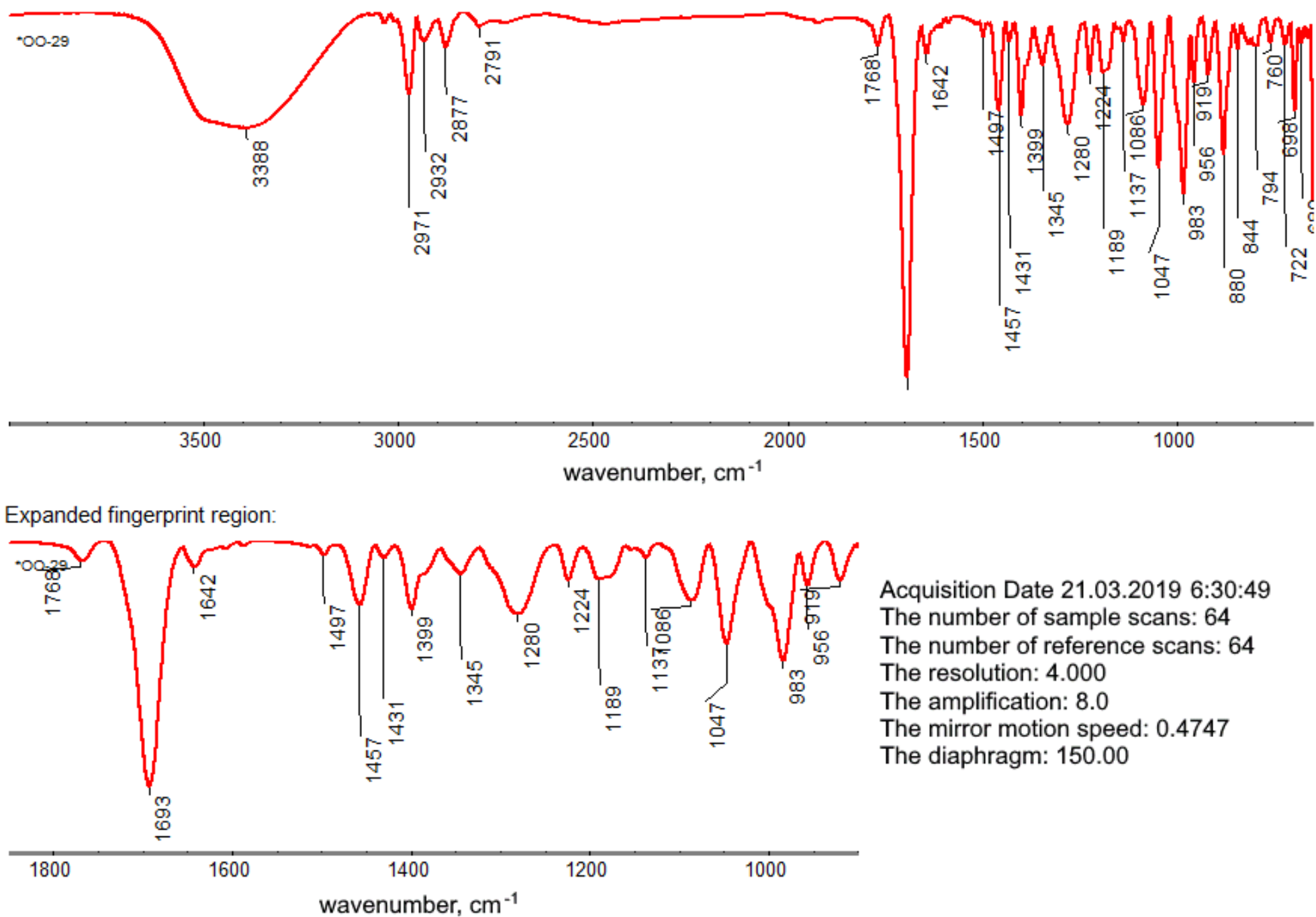

Figure S5 IR spectra of the $N$-benzylmaleimide adduct of oligomycin A endo-3a. 
Chromatogram

OO-29 C: LabSolutions \DatalOlygolOO N1116-05.lcd

$\mathrm{mAU}$

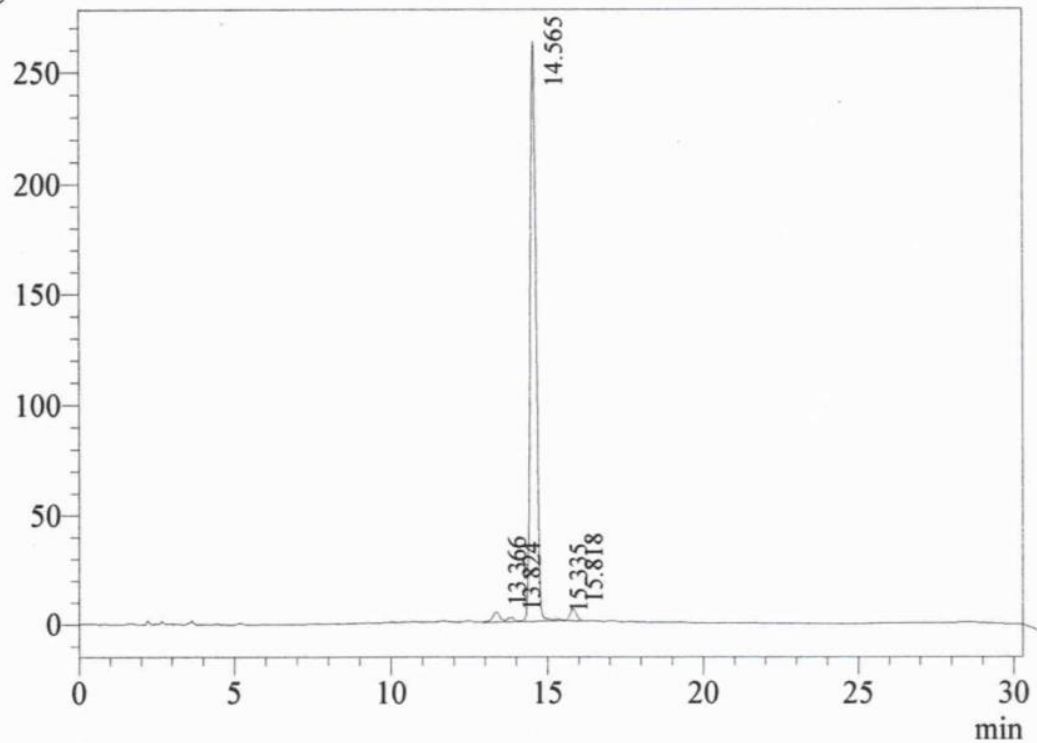

1PDA Multi 1

1 PDA Multi $1 / 230 \mathrm{~nm} 4 \mathrm{~nm}$

PeakTable

PDA Ch1 230nm 4nm

\begin{tabular}{|r|r|r|r|r|}
\hline \multicolumn{1}{|c|}{ Peak\# } & Ret. Time & \multicolumn{1}{|c|}{ Area } & Height & Area \% \\
\hline 1 & 13.366 & 65559 & 4330 & 1.831 \\
\hline 2 & 13.824 & 25418 & 1825 & 0.710 \\
\hline 3 & 14.565 & 3412353 & 262232 & 95.281 \\
\hline 4 & 15.335 & 8280 & 621 & 0.231 \\
\hline 5 & 15.818 & 69730 & 5165 & 1.947 \\
\hline Total & & 3581340 & 274172 & 100.000 \\
\hline
\end{tabular}

$<<$ LC Program $>>$

Time

0.10

10.00

30.00

33.00

45.00

Unit
Pumps
Pumps
Pumps
Pumps
Controller

Method

Sample Information

Method Filename $\quad$ : WAT Oligo.lcm

Date Acquired : :01.01.2002

Shimadzu LC-20AD; 2-System FRA, Colon Kromasil 100-C18,.size 5mkm, 4,6*250mm, N Elution: A - COOHNH4 0,2\% pH7.8 : B - MeCN, fl. 1,0 ml/min, loop 20mkl.

Figure S6 HPLC of the $N$-benzylmaleimide adduct of oligomycin A endo-3a. 


\section{Compound Spectrum List Report}

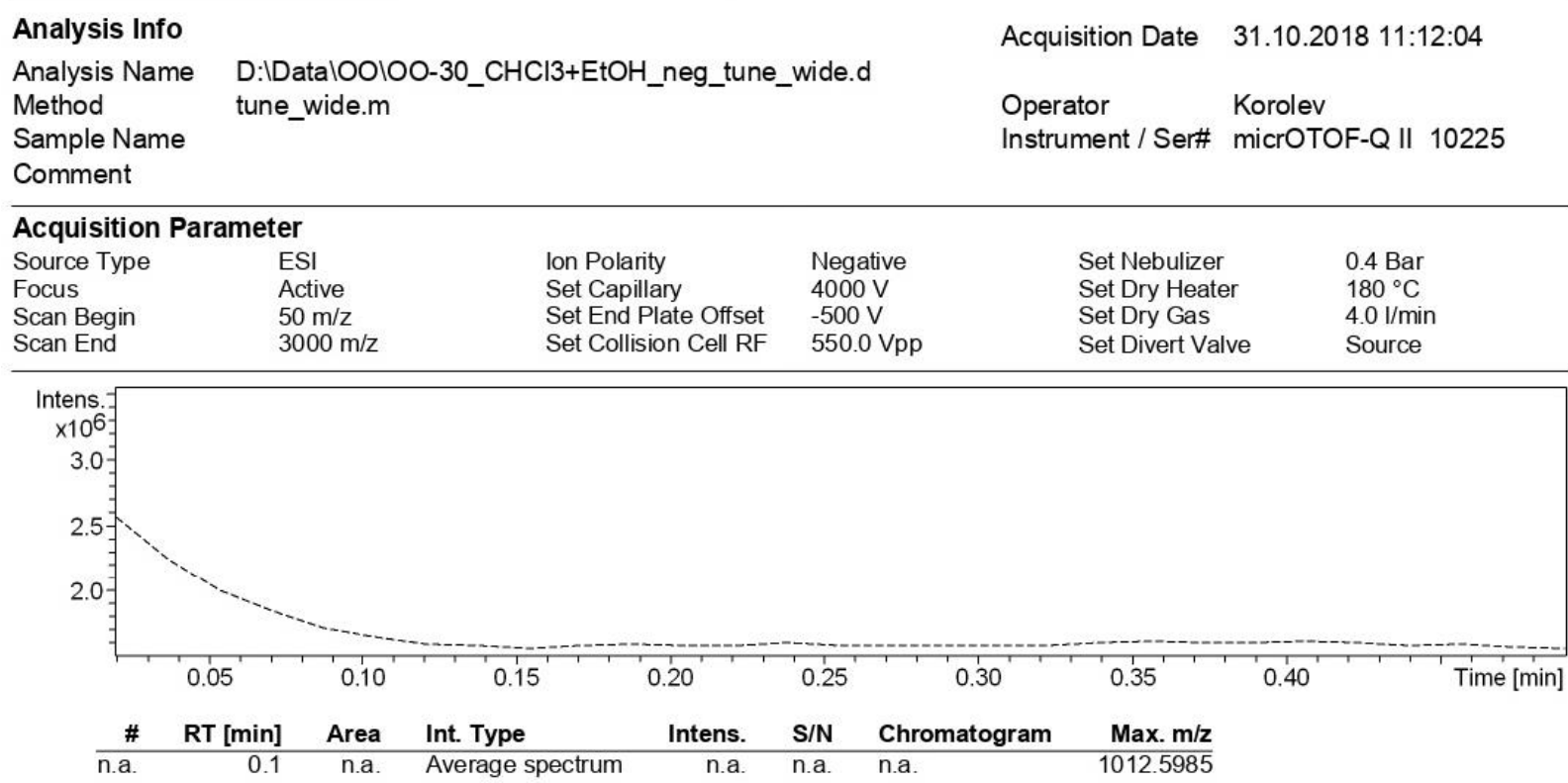

-MS, 0.0-0.1min \#(2-5)

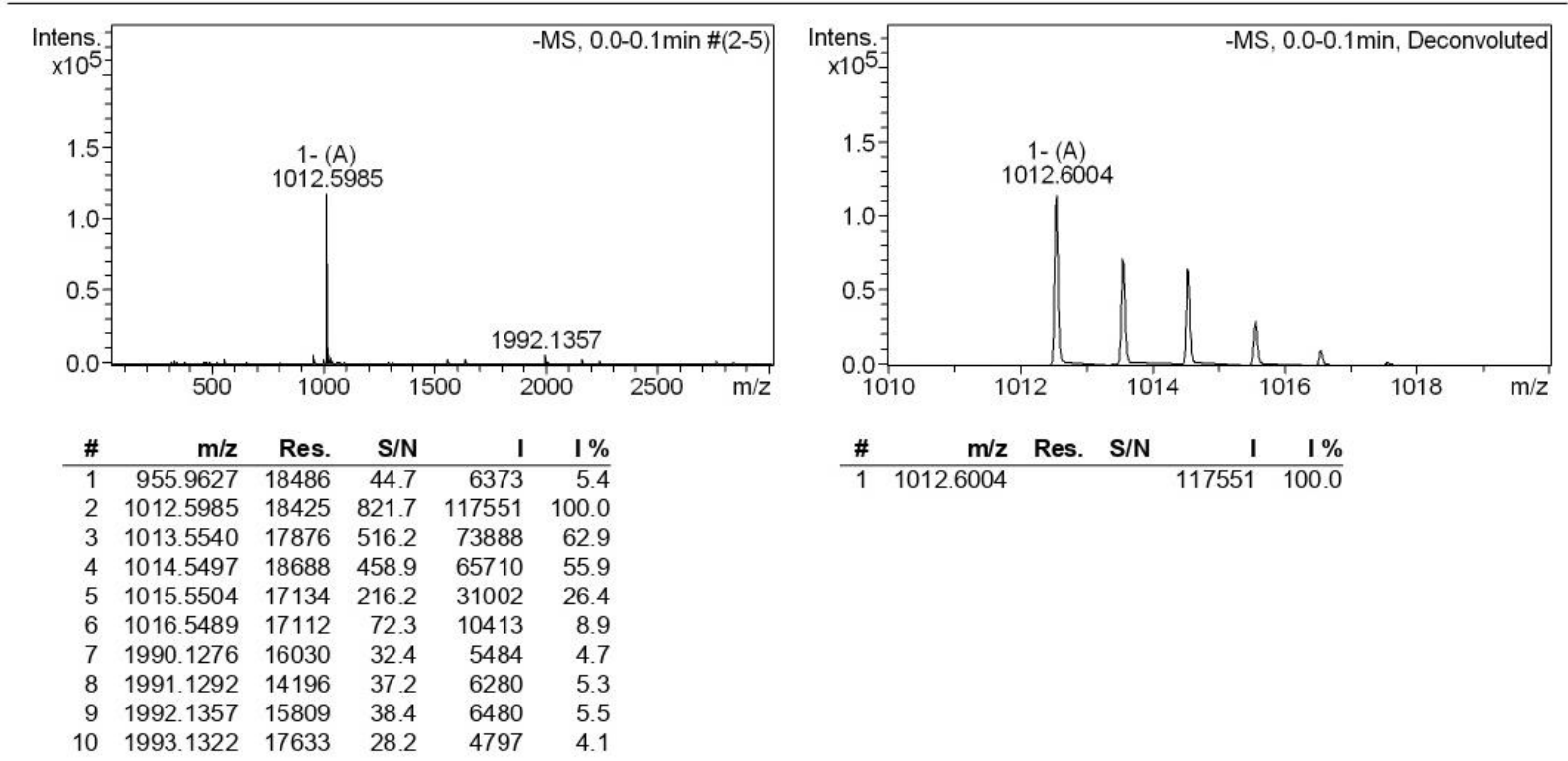

Figure S7 HRMS-ESI of the $N$-benzylmaleimide adduct of oligomycin A exo-3b. 


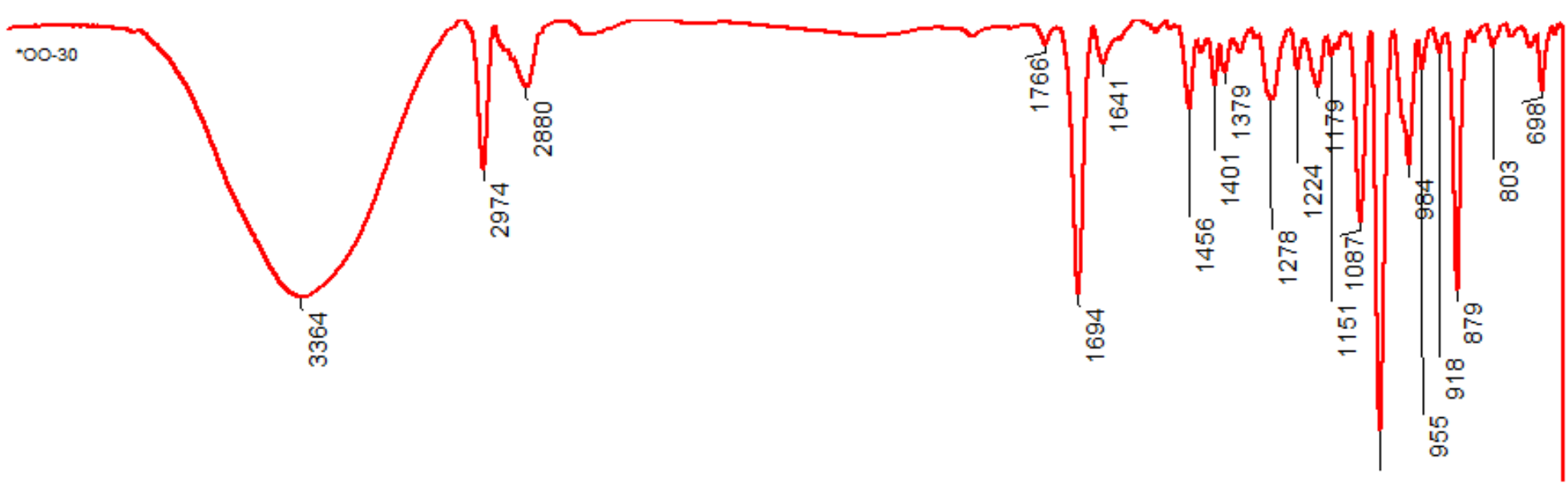

3500

3000

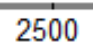

2000

1500

1000

\section{Expanded fingerprint region:}

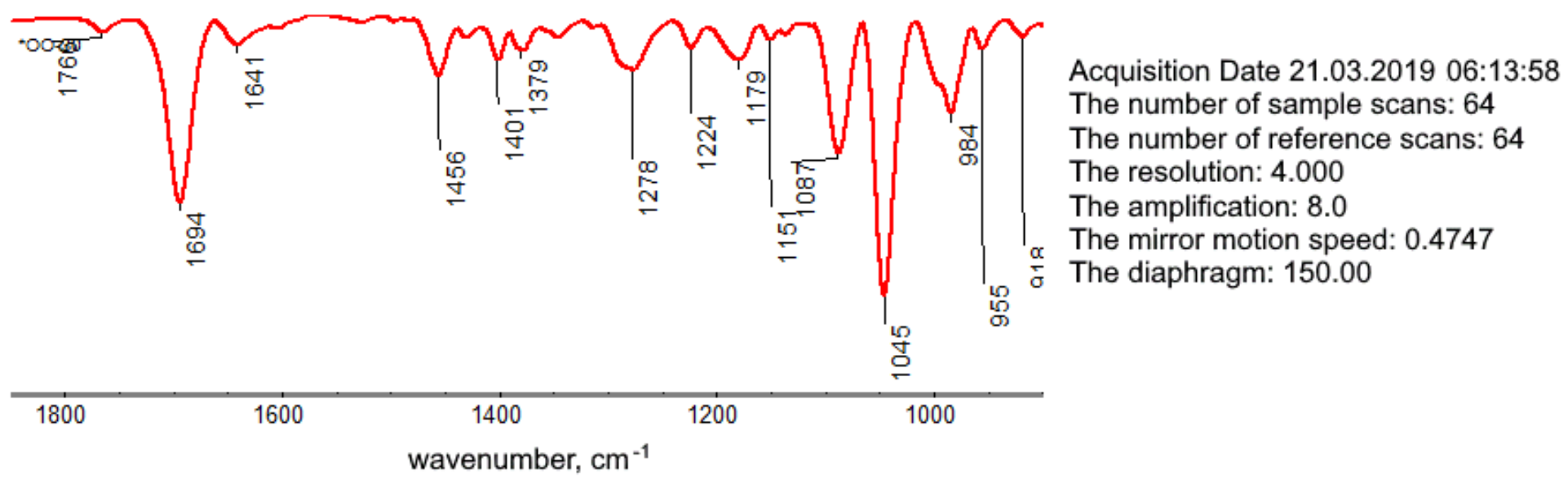

Figure S8 IR spectra of the $N$-benzylmaleimide adduct of oligomycin A exo-3b. 
Chromatogram

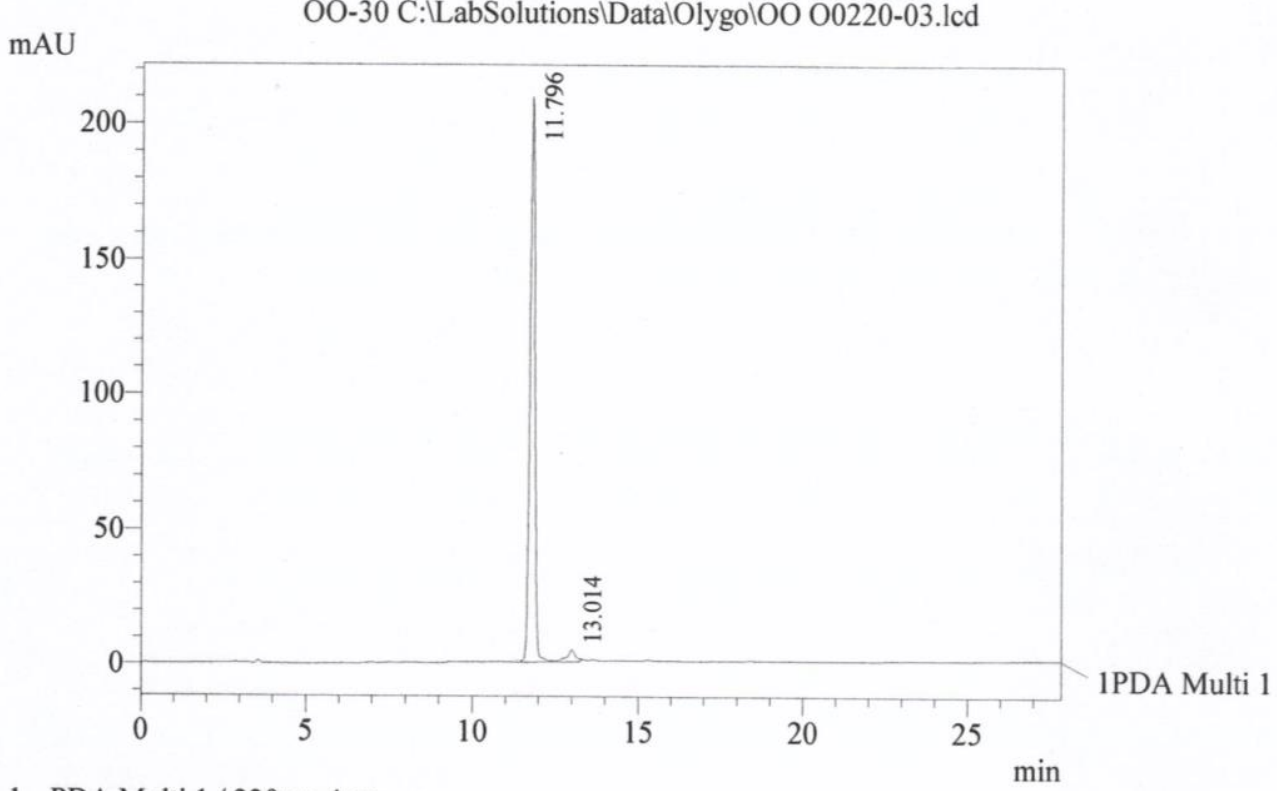

1 PDA Multi $1 / 230 \mathrm{~nm} 4 \mathrm{~nm}$

PDA Ch1 230nm 4nm
\begin{tabular}{|r|r|r|r|r|}
\hline Peak\# & Ret. Time & \multicolumn{4}{|c|}{ PeakTable } \\
\hline 1 & 11.796 & 2162527 & \multicolumn{1}{c|}{ Height } & Area \% \\
\hline 2 & 13.014 & 76971 & 209193 & 96.563 \\
\hline Total & & 2239498 & 213659 & 100.000 \\
\hline
\end{tabular}

$<<$ LC Program $>>$

Time

0.10

10.00

30.00

33.00

45.00

Unit
Pumps
Pumps
Pumps
Pumps
Controller

Method
Value

80

95

95

80

Sample Information

Method Filename : : WAT Oligo.lcm

Date Acquired $\quad: 01.01 .2002$

Shimadzu LC-20AD; 2-System FRA, Colon Kromasil 100-C18,.size 5mkm, 4,6*250mm, N 58403 Elution: A - H2O: B - MeCN, fl. 1,0 ml/min, loop $20 \mathrm{mkl}$.

Figure S9 HPLC of the $N$-benzylmaleimide adduct of oligomycin A exo-3b. 


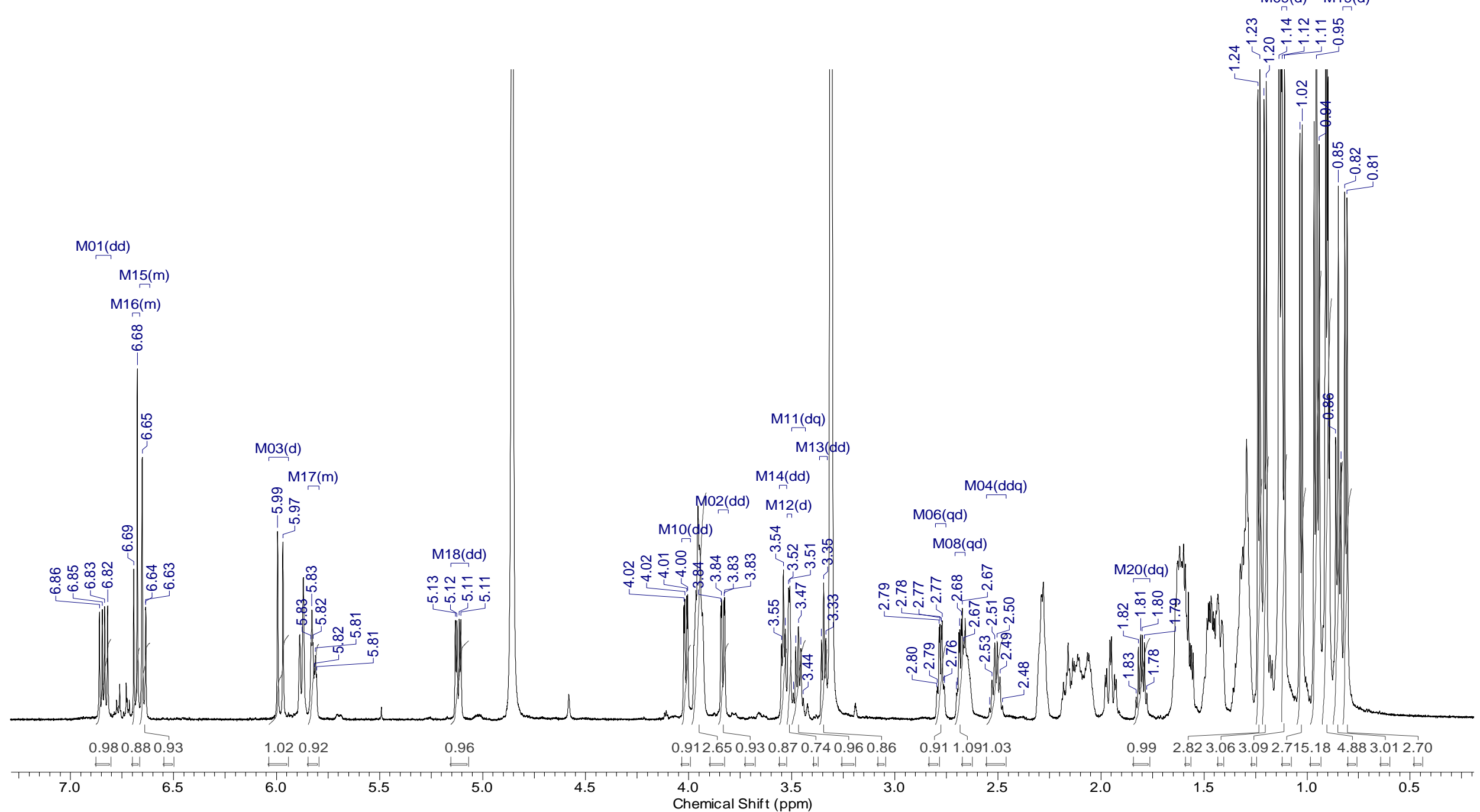

Figure S10 ${ }^{1} \mathrm{H}$ NMR spectra of the benzoquinone adduct endo-2b $\left(600 \mathrm{MHz}, \mathrm{CD}_{3} \mathrm{OD}\right)$. 


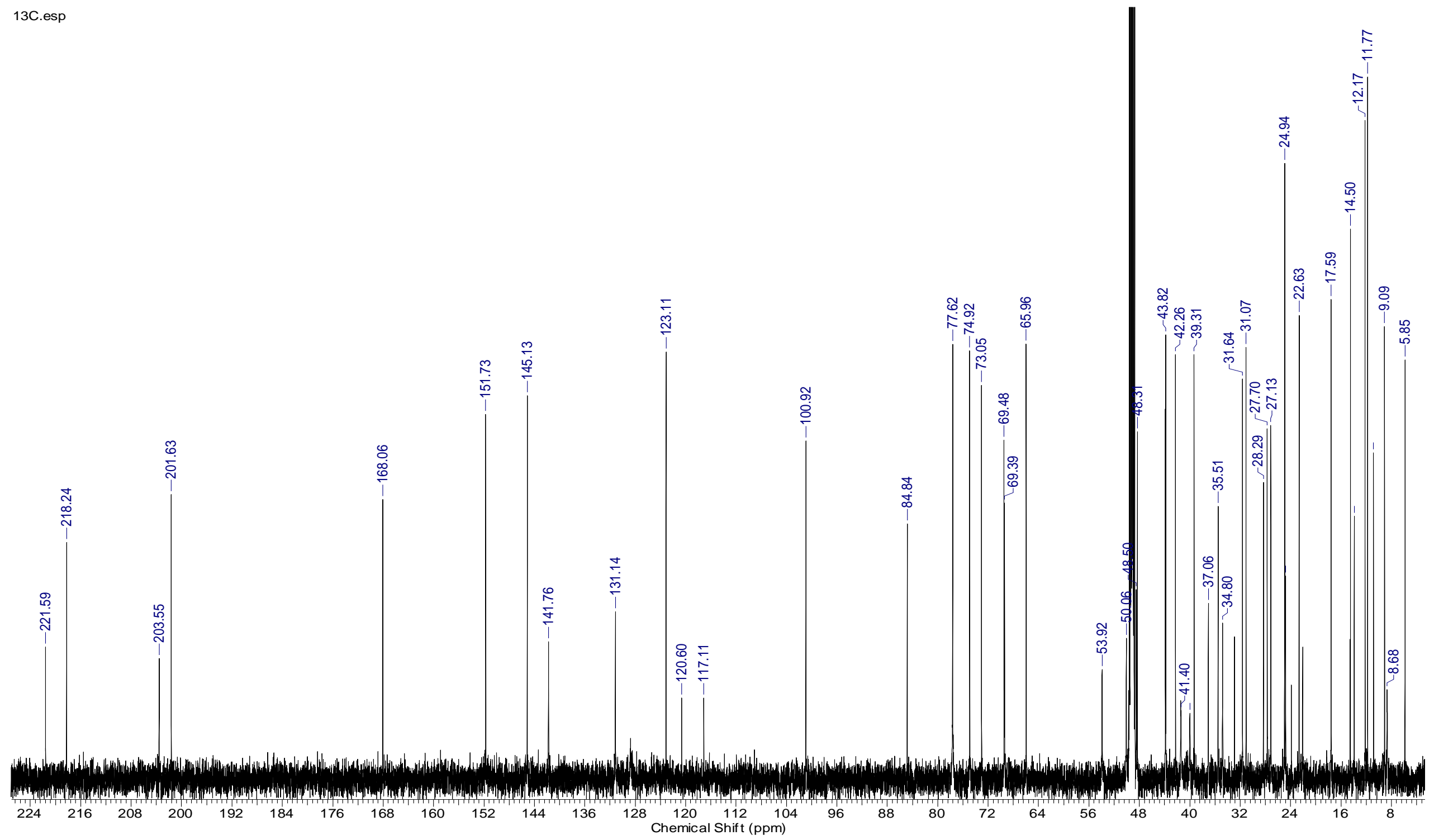

Figure S11 ${ }^{13} \mathrm{C}$ NMR spectra of the benzoquinone adduct endo-2b $\left(150 \mathrm{MHz}, \mathrm{CD}_{3} \mathrm{OD}\right)$. 


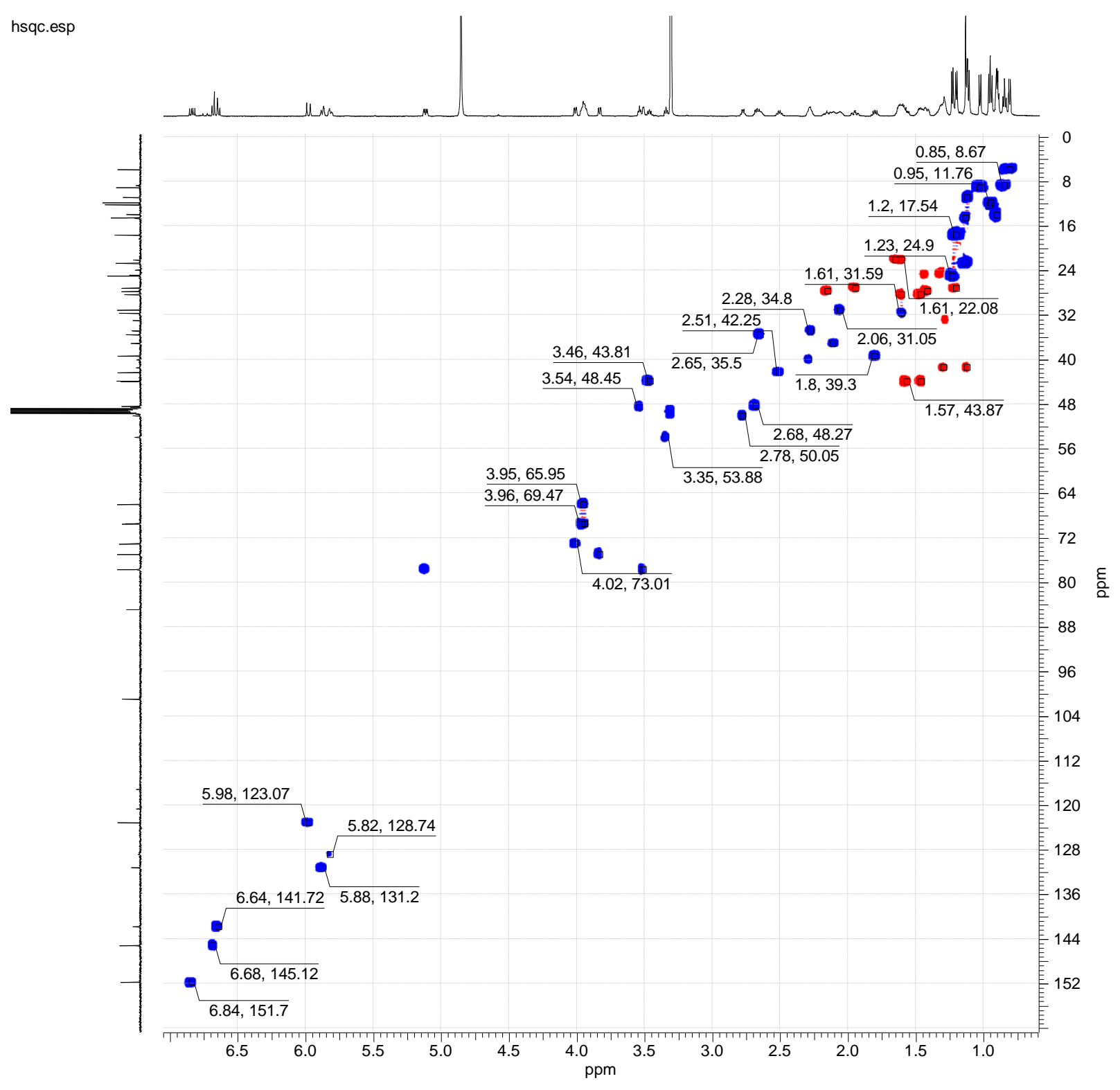

Figure S12 ${ }^{1} \mathrm{H}_{-}{ }^{13} \mathrm{C}$ HSQC NMR spectrum of the benzoquinone adduct endo-2b $\left(\mathrm{CD}_{3} \mathrm{OD}\right)$. 


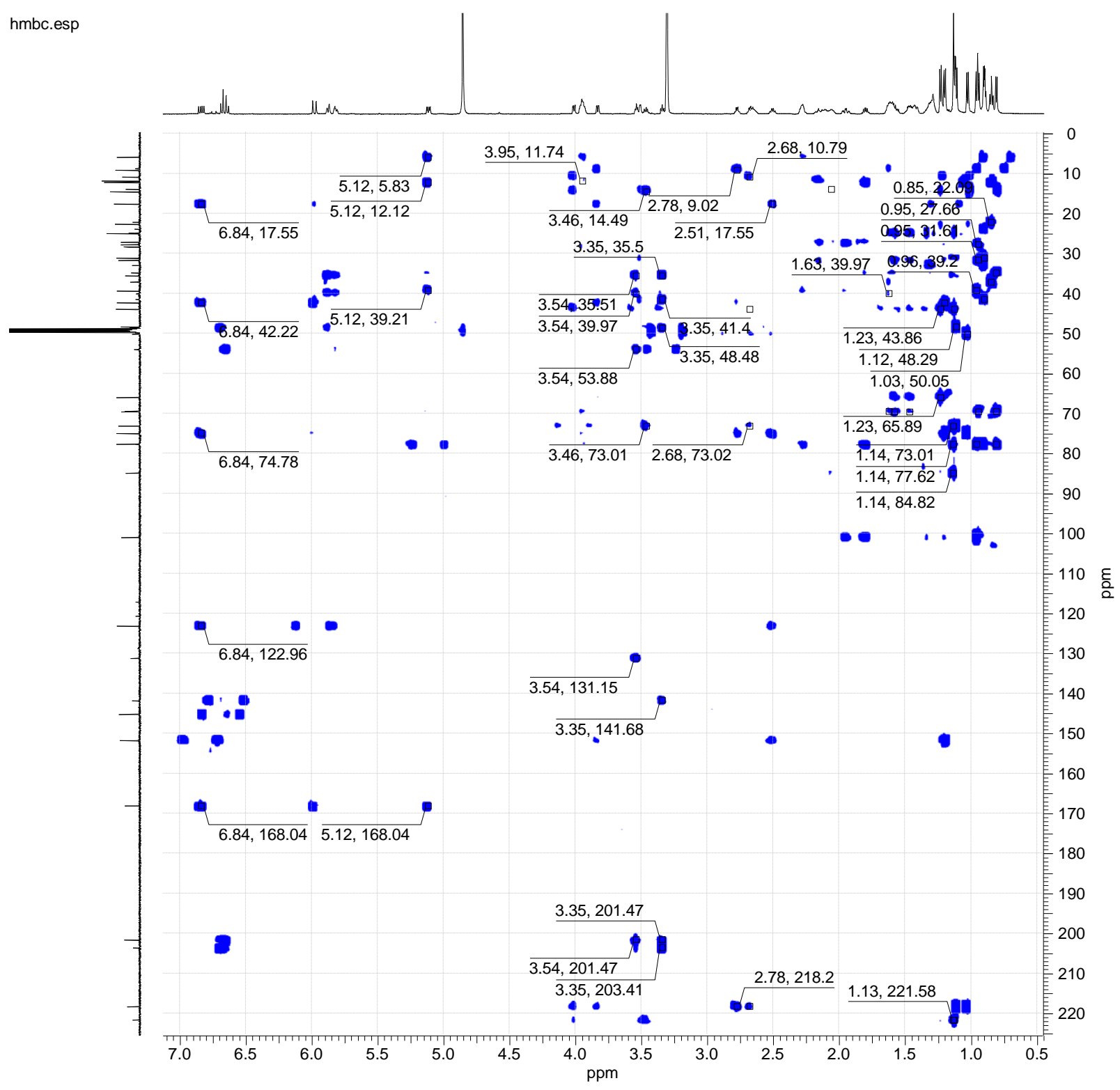

Figure S13 ${ }^{1} \mathrm{H}-{ }^{13} \mathrm{C}$ HMBC NMR spectrum of the benzoquinone adduct endo-2b $\left(\mathrm{CD}_{3} \mathrm{OD}\right)$. 


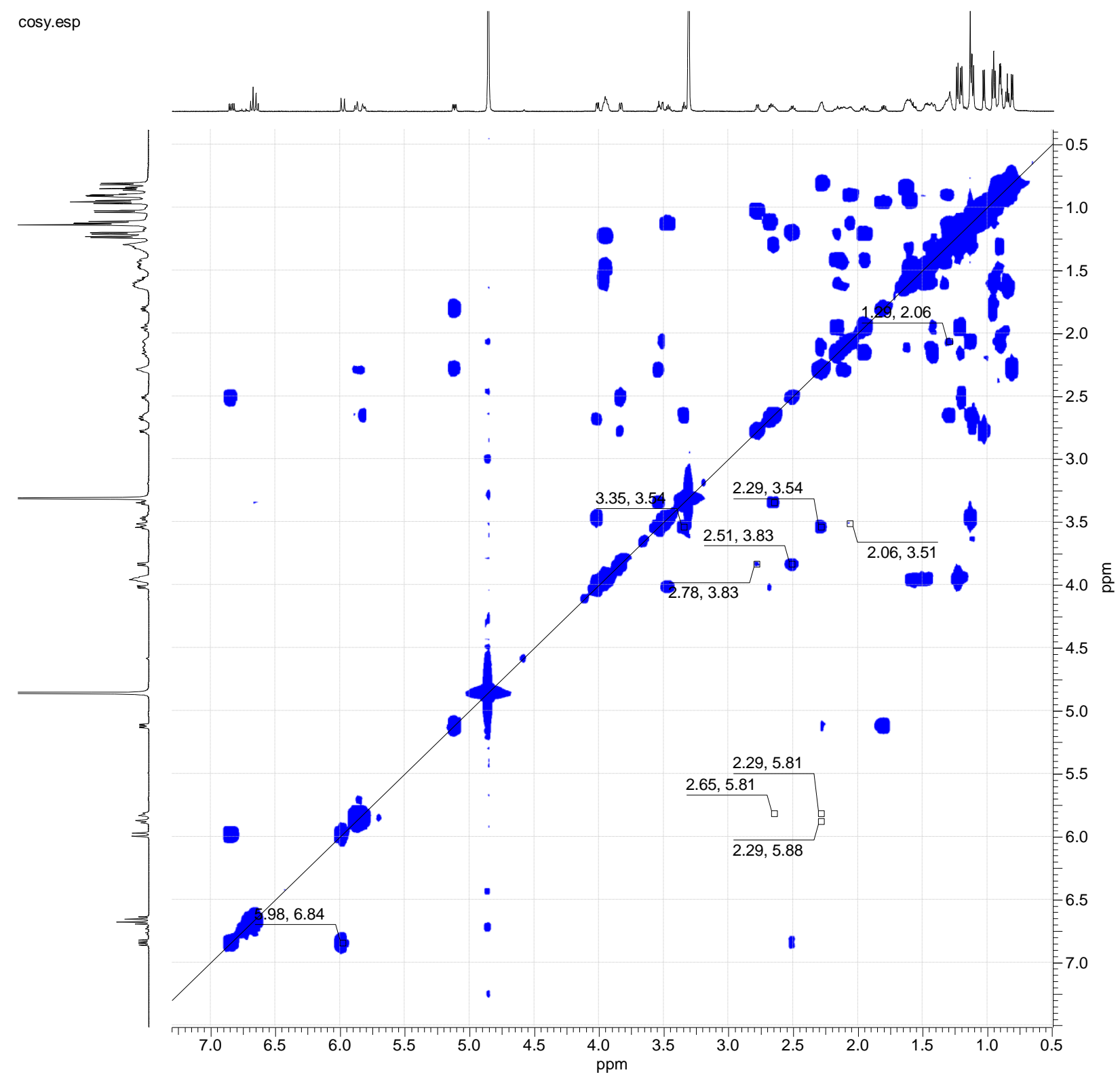

Figure S14 ${ }^{1} \mathrm{H}-{ }^{1} \mathrm{H}$ COSY NMR spectrum of the benzoquinone adduct endo-2b $\left(\mathrm{CD}_{3} \mathrm{OD}\right)$. 


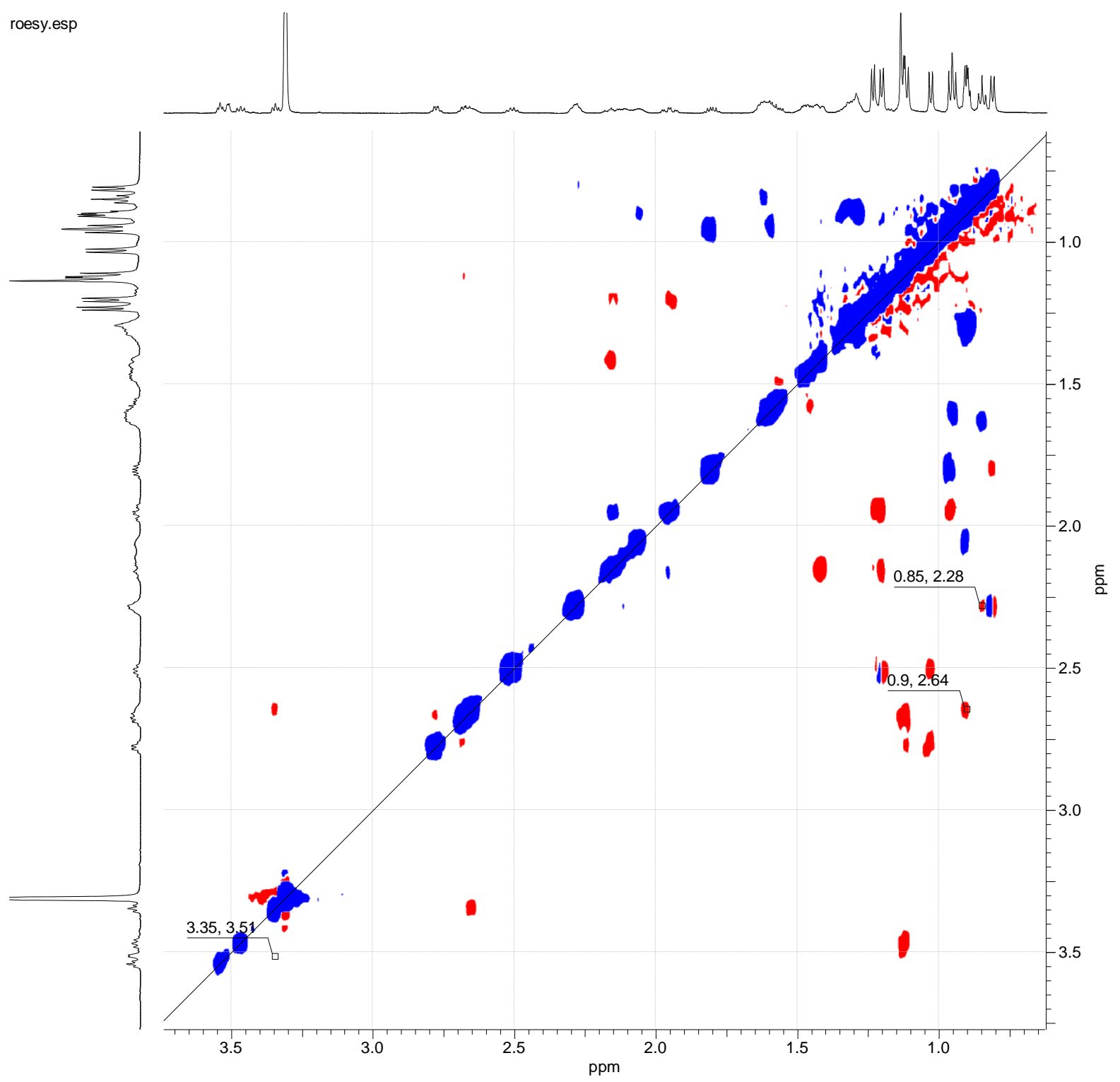

Figure S15 ${ }^{1} \mathrm{H}-{ }^{1} \mathrm{H}$ ROESY NMR spectrum of the benzoquinone adduct endo-2b $\left(\mathrm{CD}_{3} \mathrm{OD}\right)$. 


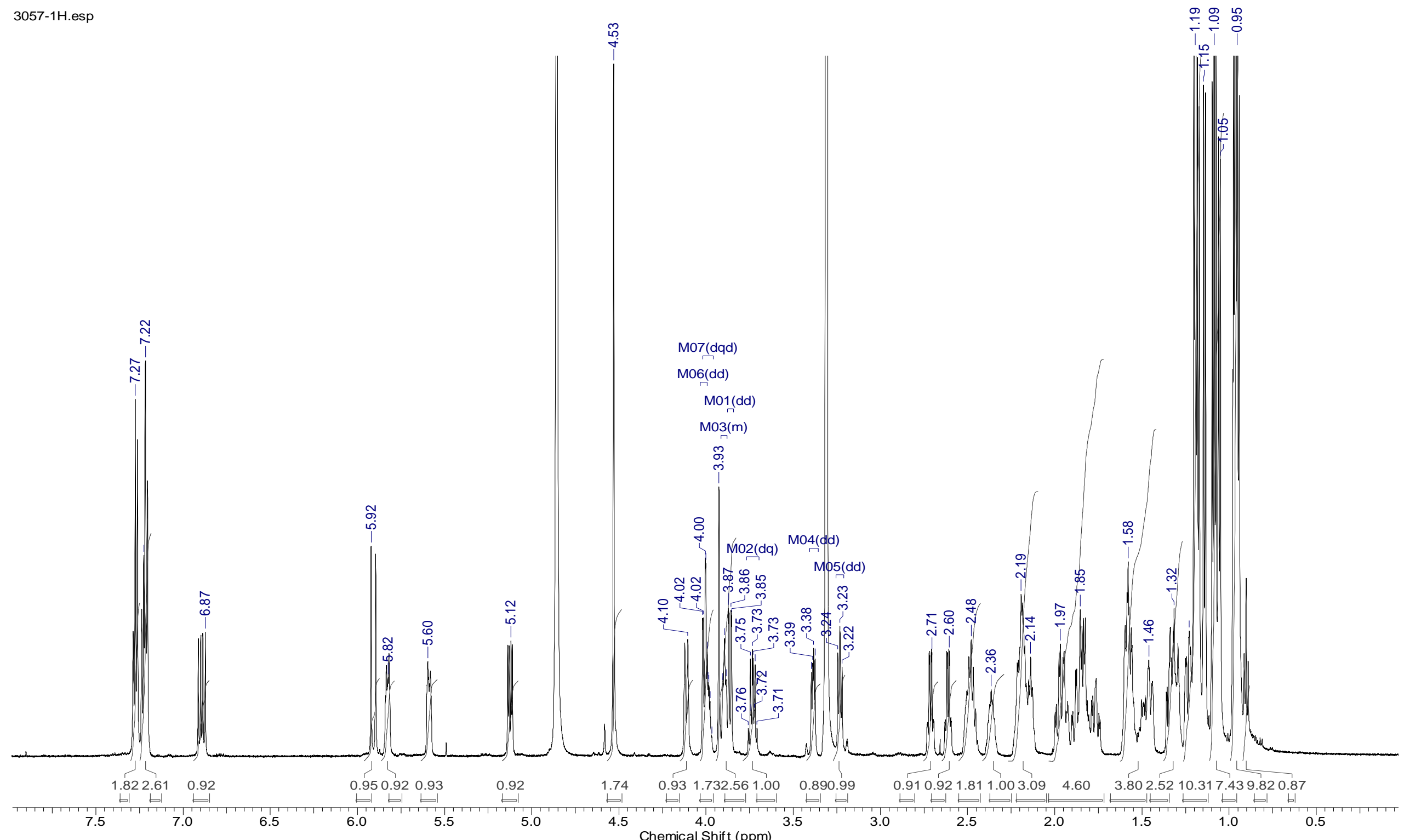

Figure S16 ${ }^{1} \mathrm{H}$ NMR spectrum of the N-benzylmaleimide adduct endo-3a (600 MHz, CD3OD). 


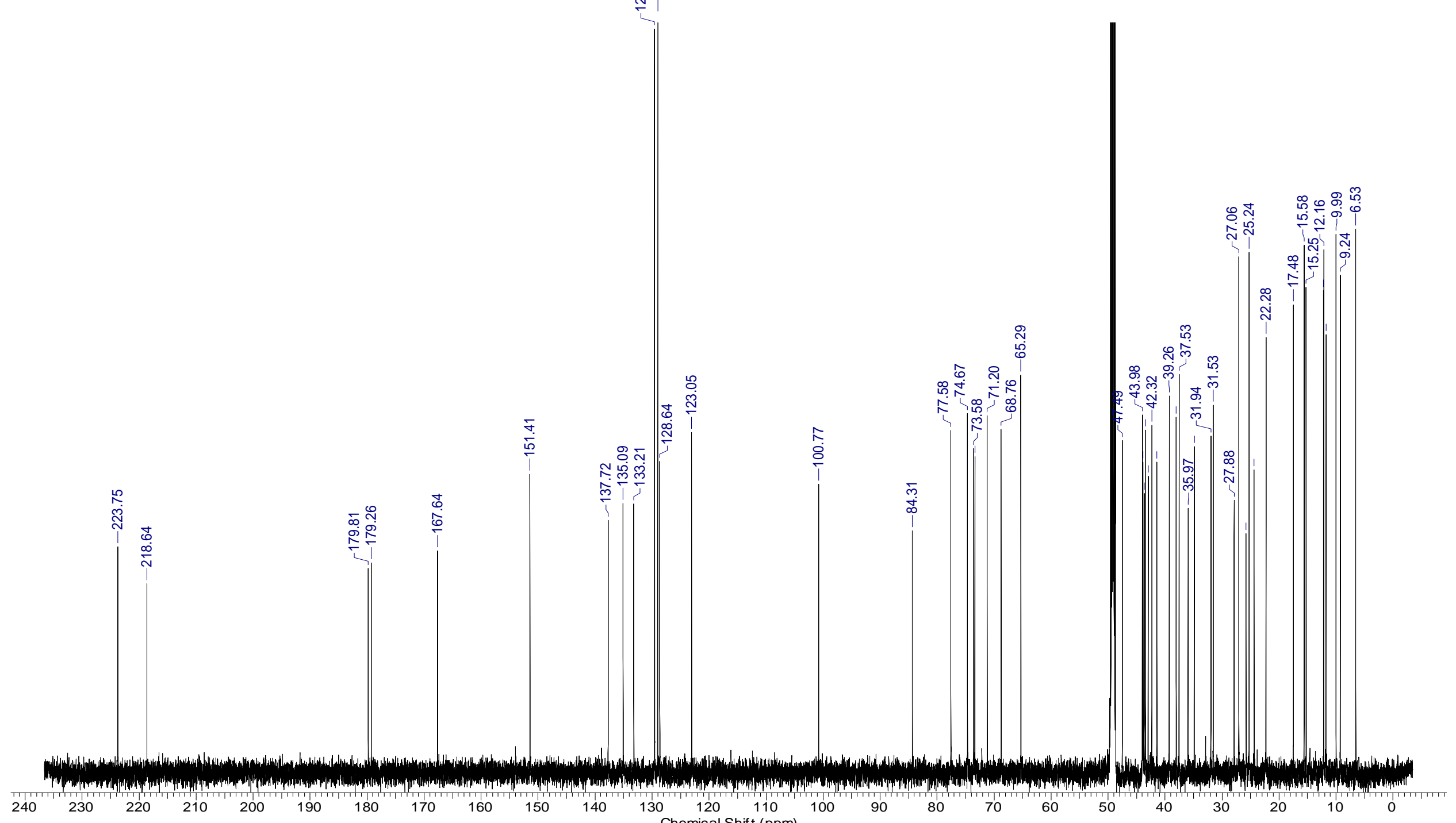

Figure $\mathbf{S 1 7}{ }^{13} \mathrm{C}$ NMR spectrum of the $N$-benzylmaleimide adduct endo-3a $\left(150 \mathrm{MHz}, \mathrm{CD}_{3} \mathrm{OD}\right)$. 


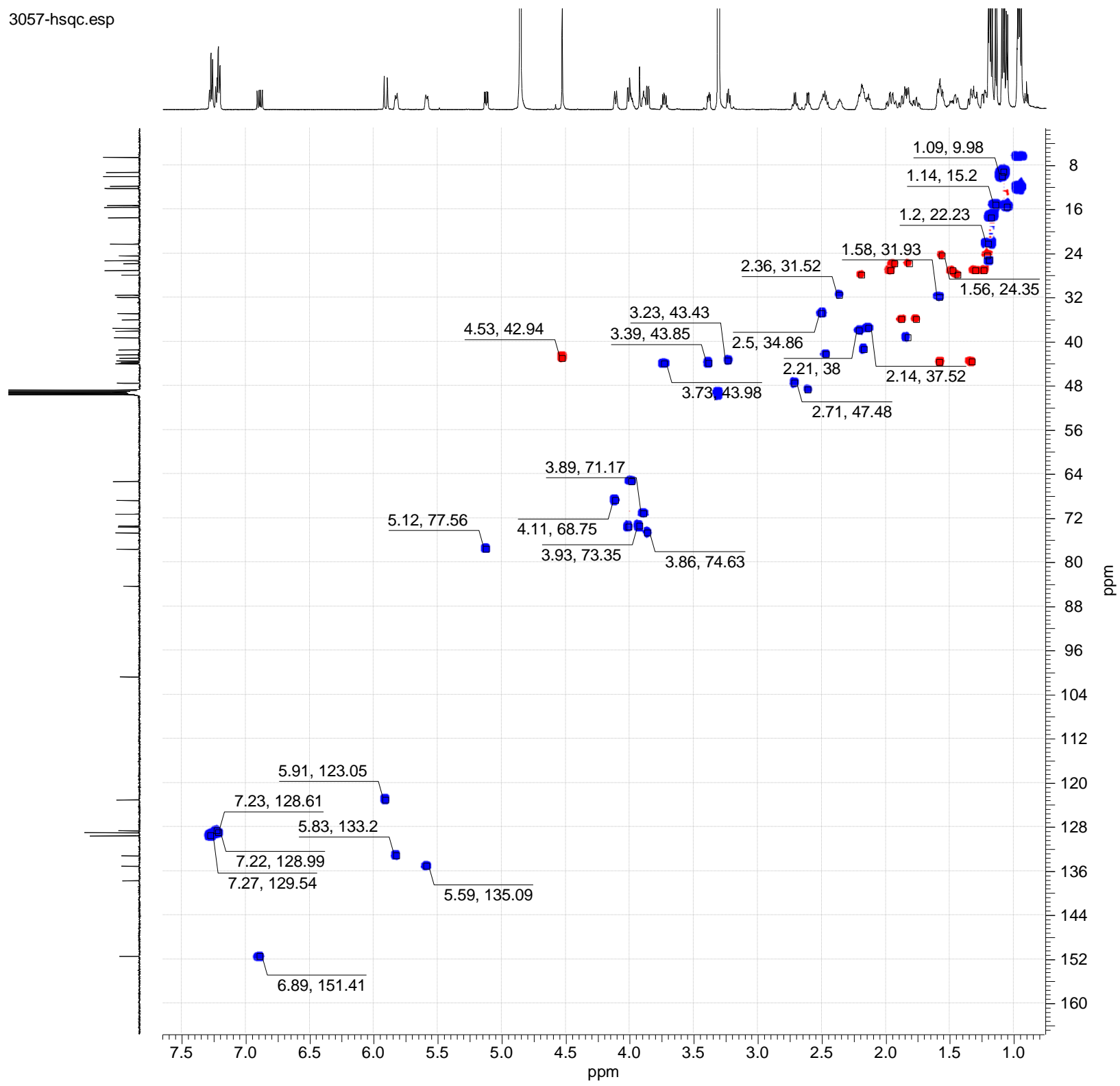

Figure $\mathbf{S 1 8}{ }^{1} \mathrm{H}_{-}{ }^{13} \mathrm{C}$ HSQC NMR spectrum of the $N$-benzylmaleimide adduct endo-3a $\left(\mathrm{CD}_{3} \mathrm{OD}\right)$. 


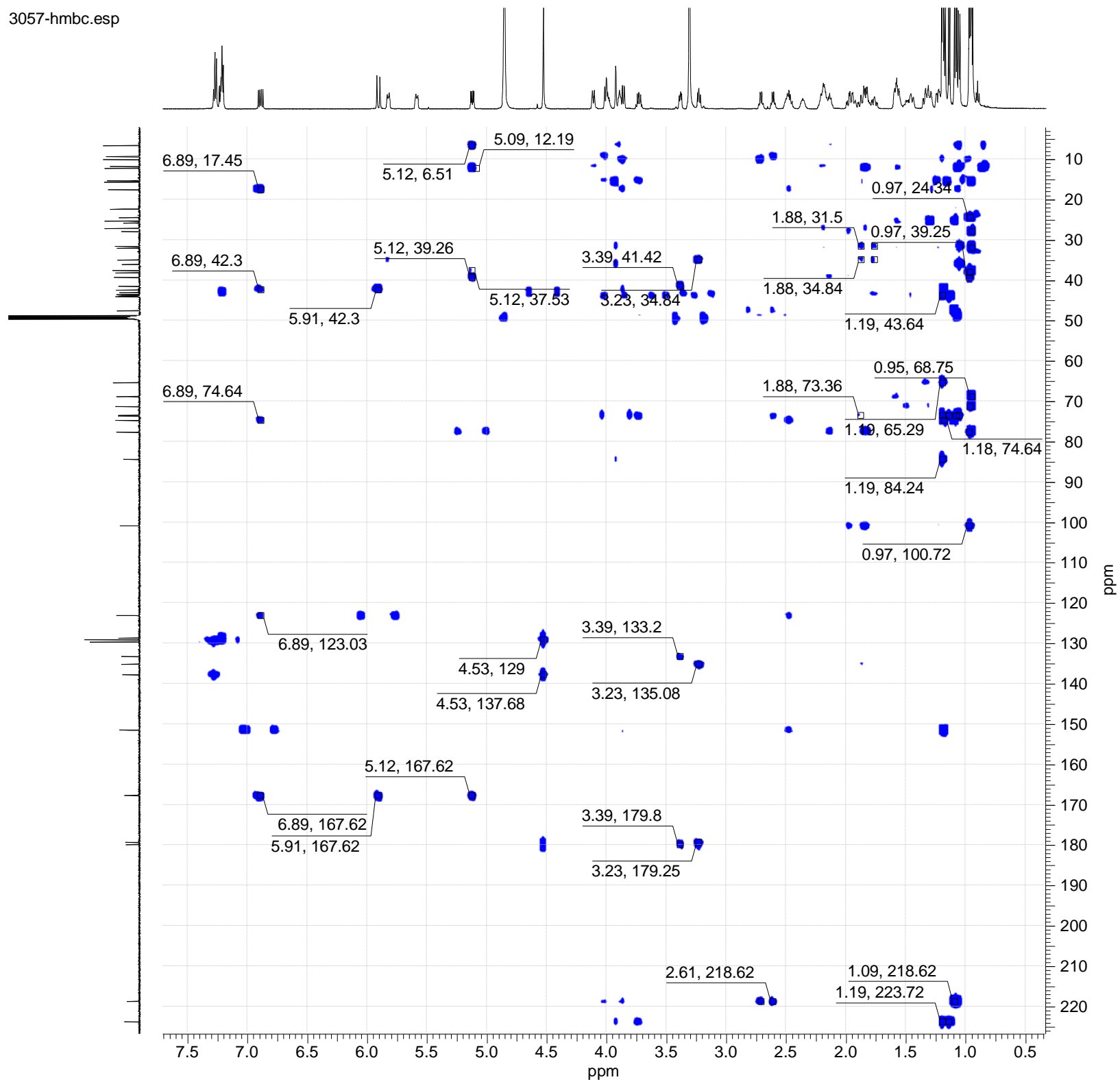

Figure S19 ${ }^{1} \mathrm{H}-{ }^{13} \mathrm{C}$ HMBC NMR spectrum of the $N$-benzylmaleimide adduct endo-3a $\left(\mathrm{CD}_{3} \mathrm{OD}\right)$. 


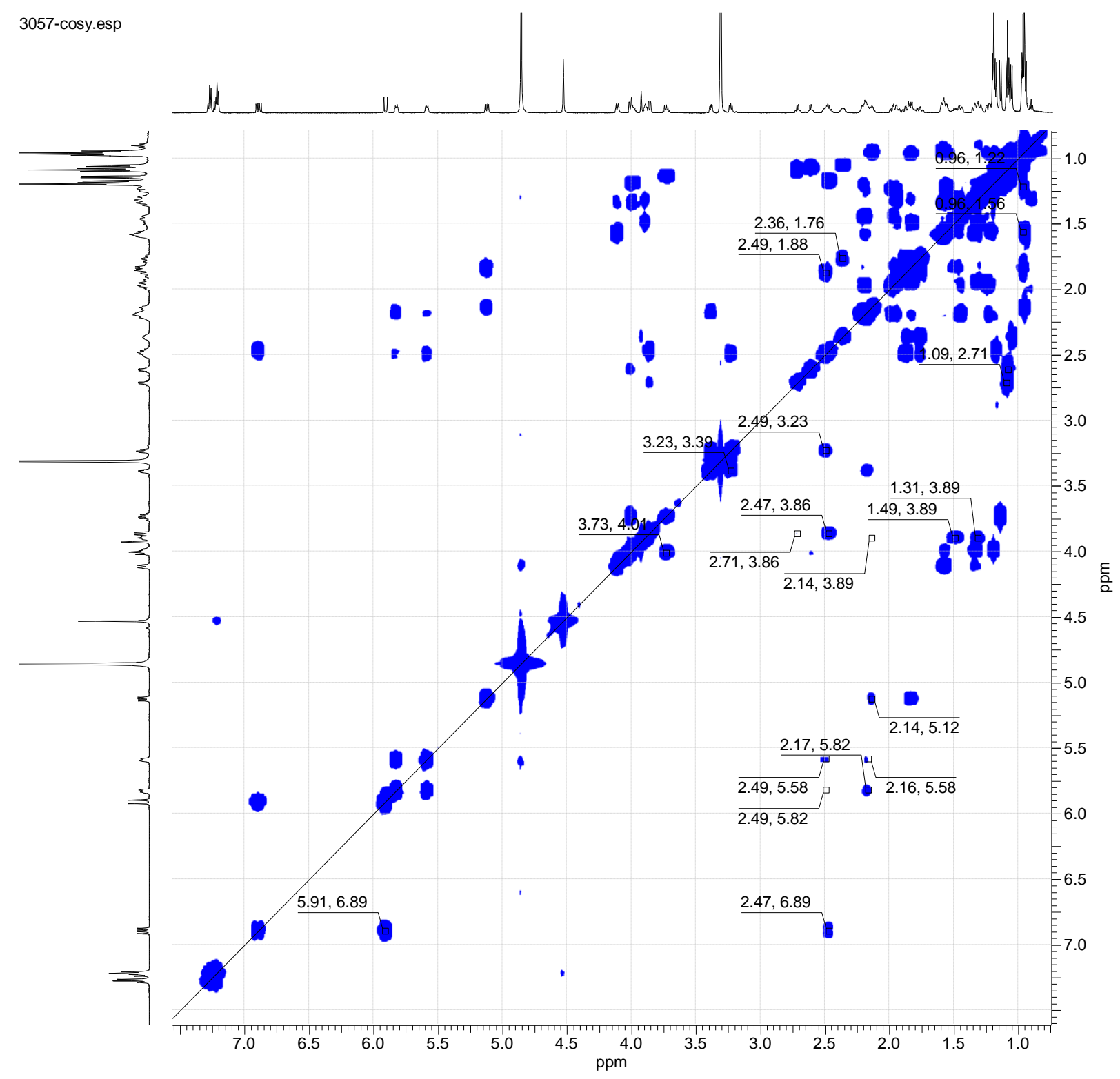

Figure S20 ${ }^{1} \mathrm{H}-{ }^{1} \mathrm{H}$ COSY NMR spectrum of the $N$-benzylmaleimide adduct endo-3a $\left(\mathrm{CD}_{3} \mathrm{OD}\right)$. 


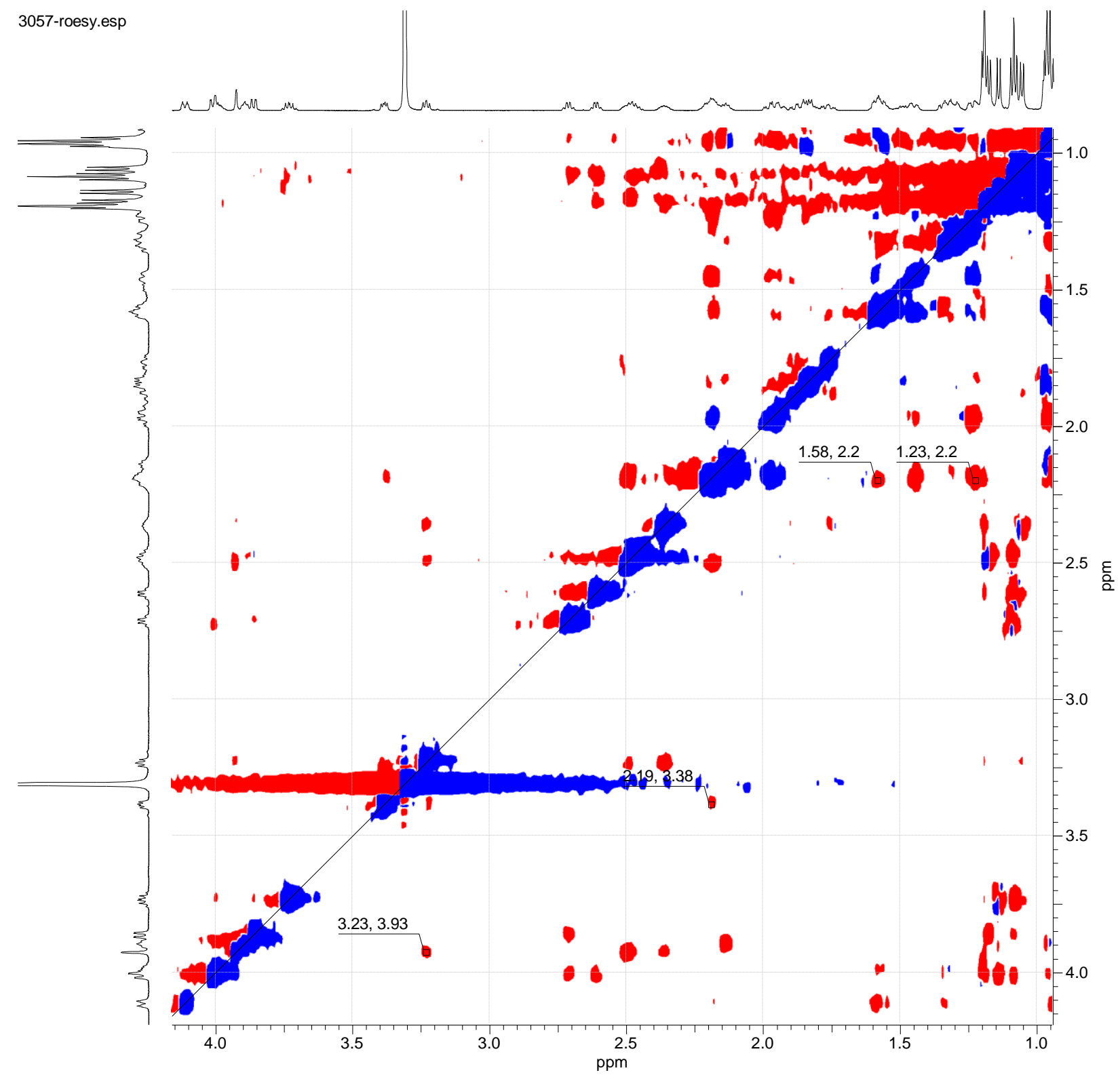

Figure S21 ${ }^{1} \mathrm{H}-{ }^{1} \mathrm{H}$ ROESY NMR spectrum of the $N$-benzylmaleimide adduct endo-3a $\left(\mathrm{CD}_{3} \mathrm{OD}\right)$. 


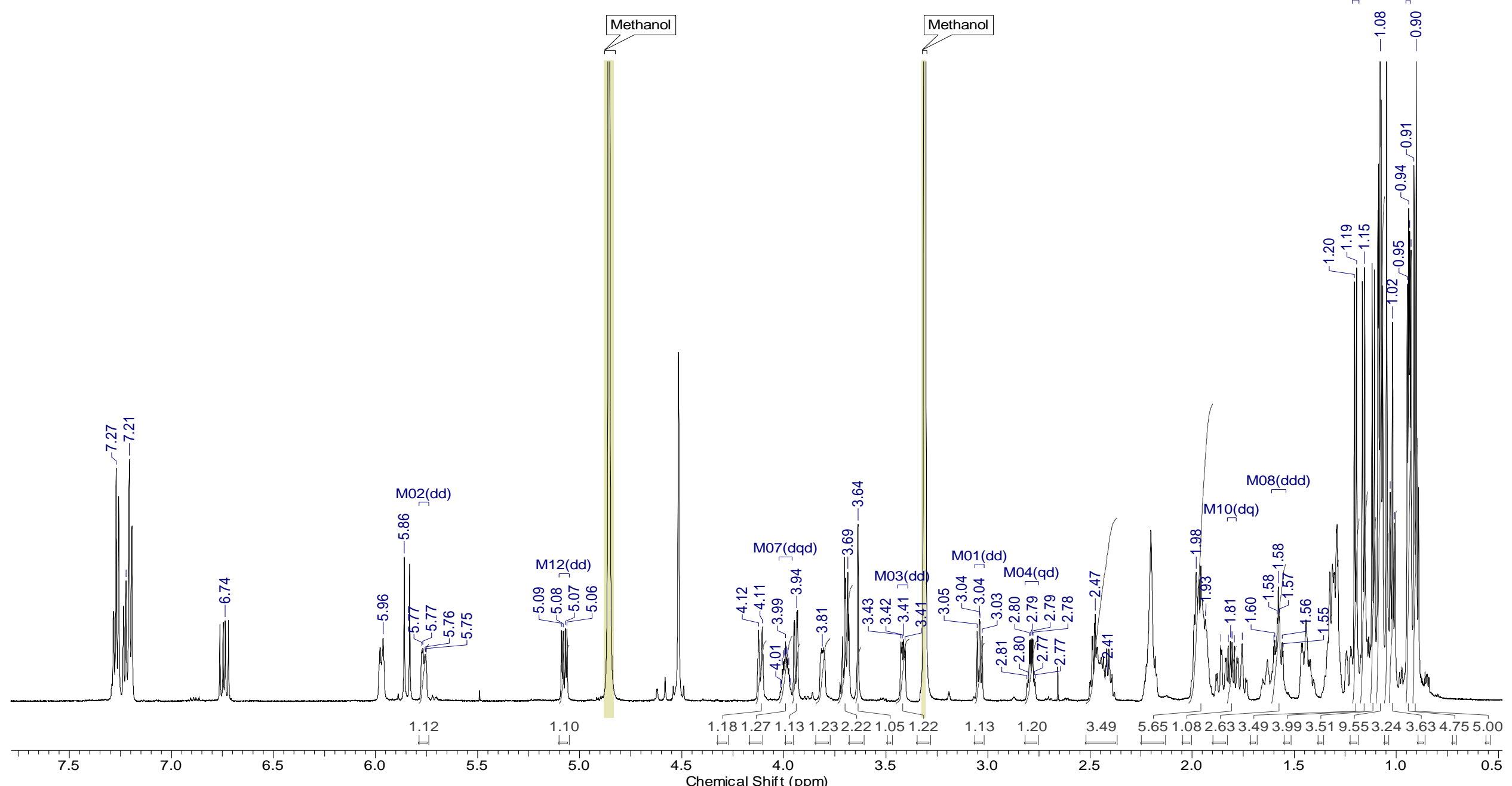

Figure S22 ${ }^{1} \mathrm{H}$ NMR spectrum of the $N$-benzylmaleimide adduct exo-3b $\left(600 \mathrm{MHz}, \mathrm{CD}_{3} \mathrm{OD}\right)$. 


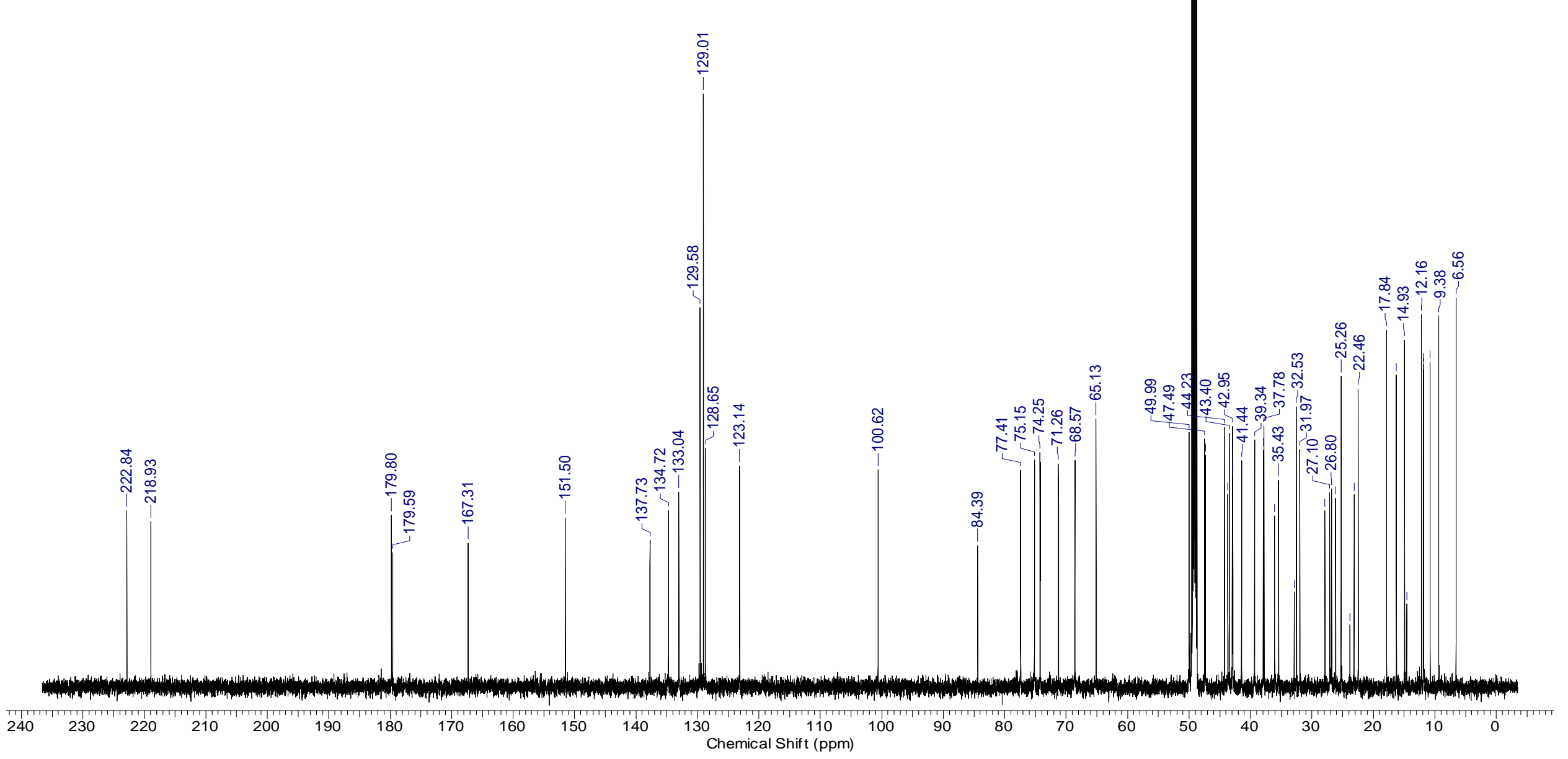

Figure S23 ${ }^{13} \mathrm{C}$ NMR spectrum of the $N$-benzylmaleimide adduct exo-3b $\left(150 \mathrm{MHz}, \mathrm{CD}_{3} \mathrm{OD}\right)$. 


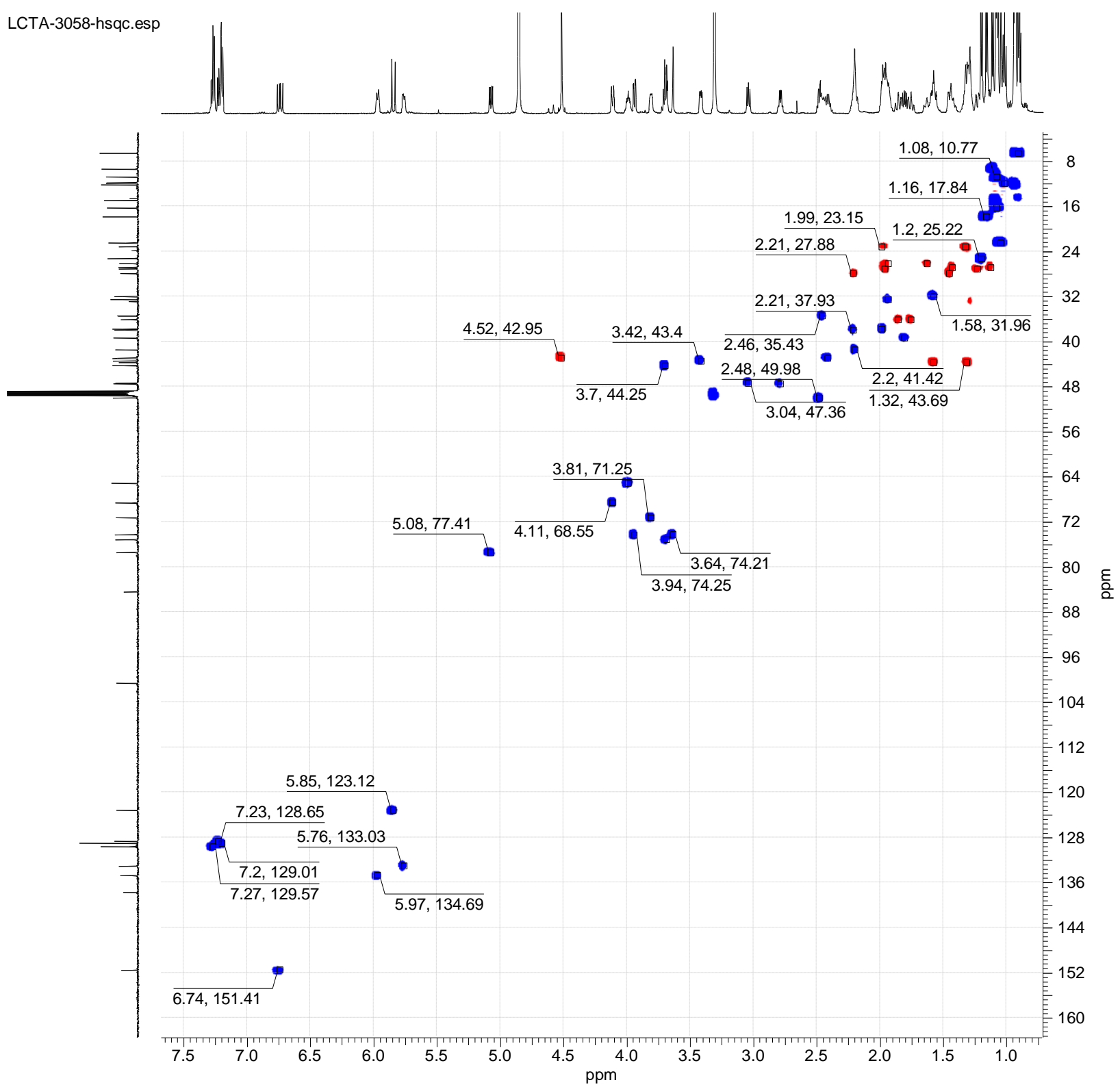

Figure S24 ${ }^{1} \mathrm{H}_{-}{ }^{13} \mathrm{C}$ HSQC NMR spectrum of the $N$-benzylmaleimide adduct exo-3b $\left(\mathrm{CD}_{3} \mathrm{OD}\right)$. 


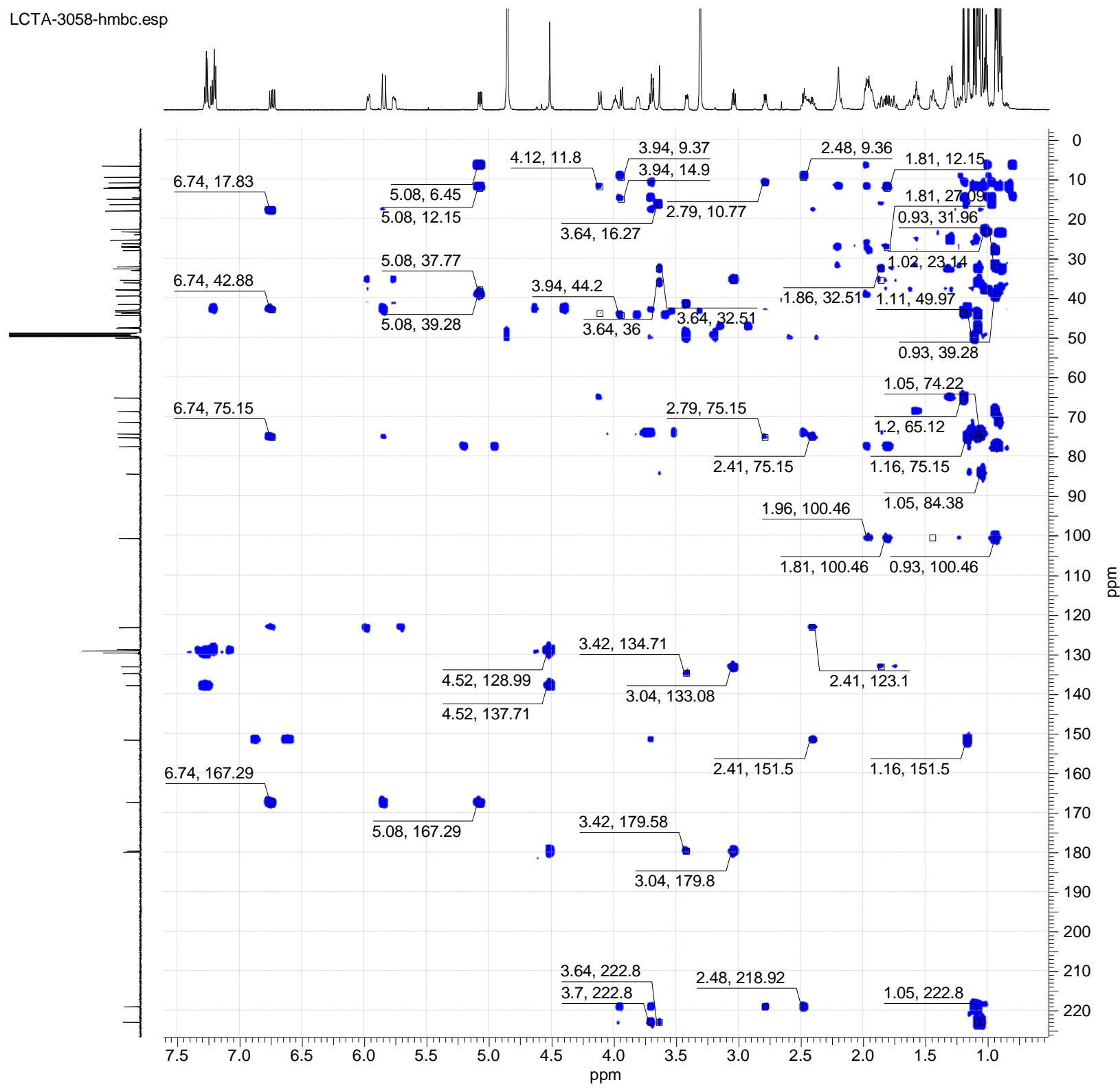

Figure S25 ${ }^{1} \mathrm{H}-{ }^{13} \mathrm{C}$ HMBC NMR spectrum of the $N$-benzylmaleimide adduct exo-3b $\left(\mathrm{CD}_{3} \mathrm{OD}\right)$. 


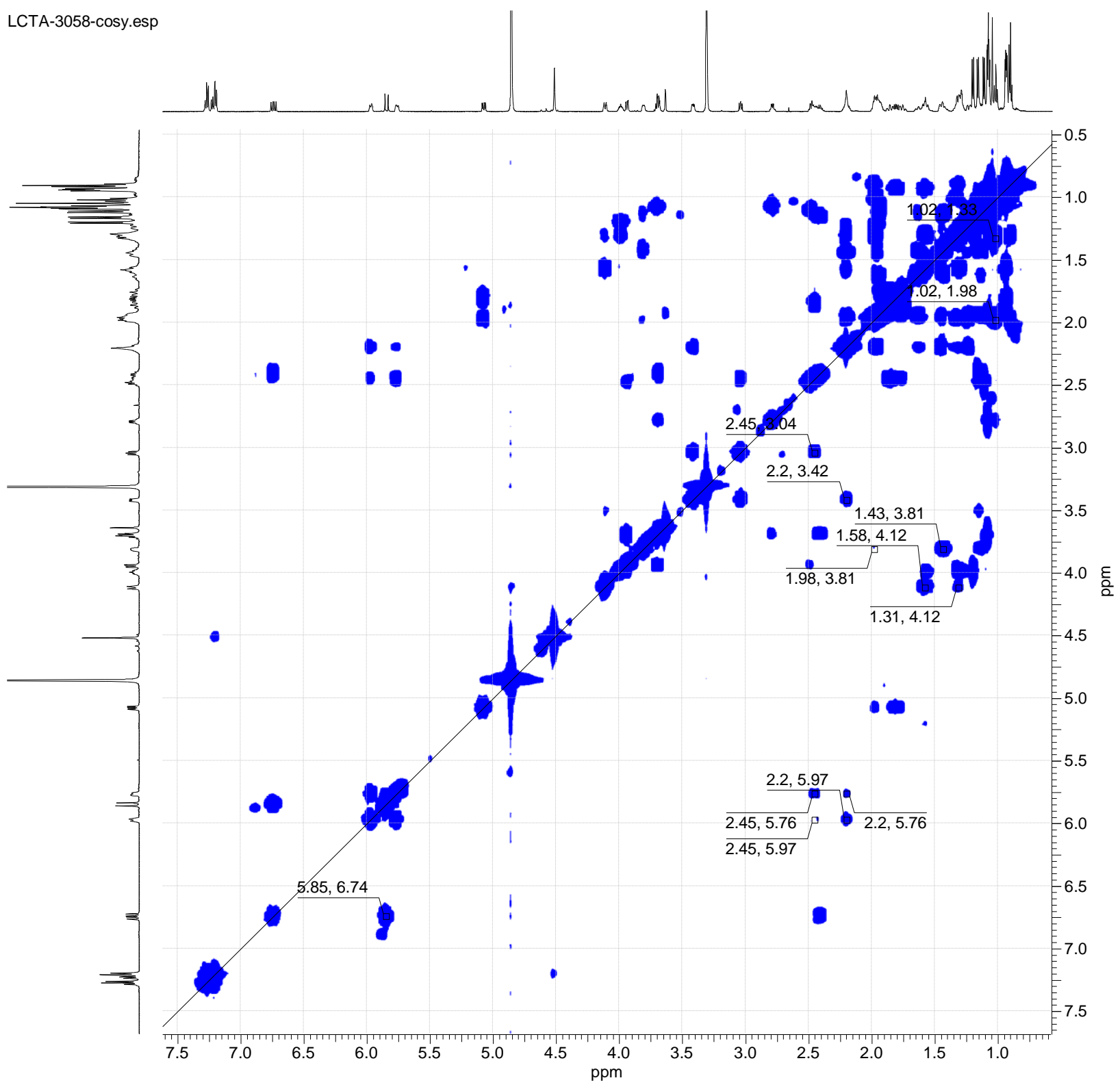

Figure S26 ${ }^{1} \mathrm{H}-{ }^{1} \mathrm{H}$ COSY NMR spectrum of the $N$-benzylmaleimide adduct exo-3b $\left(\mathrm{CD}_{3} \mathrm{OD}\right)$. 


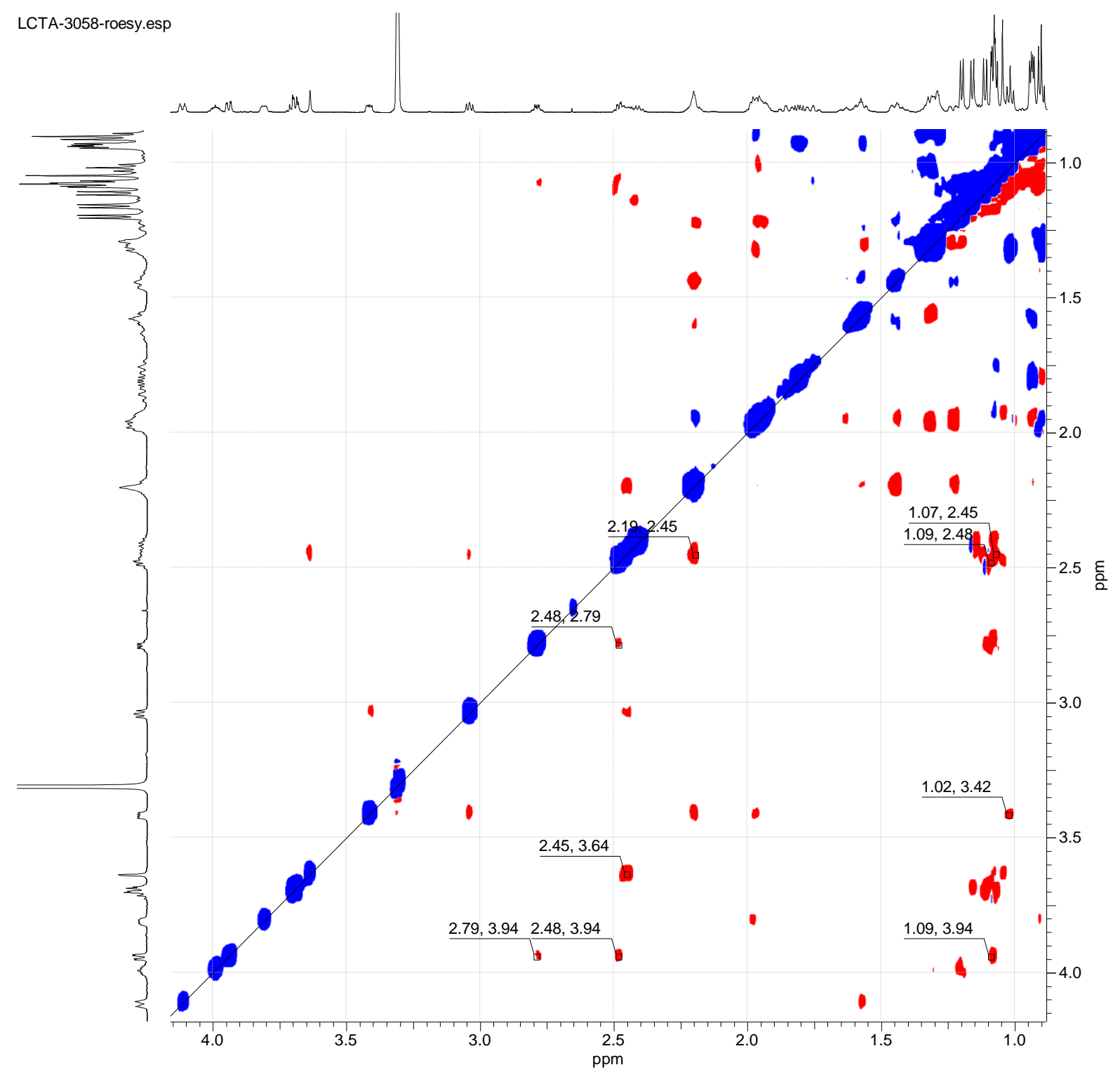

Figure S27 ${ }^{1} \mathrm{H}-{ }^{1} \mathrm{H}$ ROESY NMR spectrum of the cis-exo $N$-benzylmaleimide adduct exo-3b $\left(\mathrm{CD}_{3} \mathrm{OD}\right)$. 


\section{Geometries optimization and calculation of the free energies of s-cis and s- trans oligomycin conformations}

The conformational searches for $s$-cis and s-trans conformations were performed using MacroModel with constraints on the C17-C55-C56-C2 torsion angle $\left(0^{\circ}\right.$ or $180^{\circ}$, see Figure S28). These conformational searches provided 55 structures in total, which were then optimized in Gaussian16.

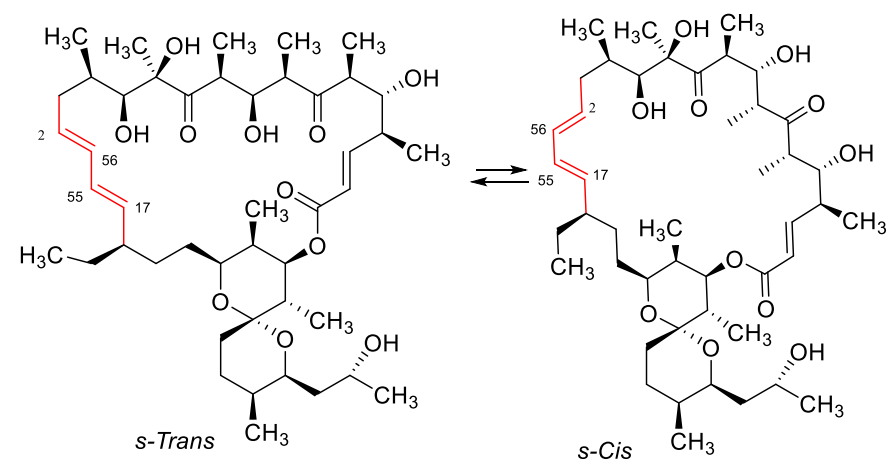

Figure S28. Two possible conformations of the Oligomycin A diene moiety. Atoms for which a larger basis set was used are colored in red.

All located transition states were compared to each other by means of RMSD of all nonhydrogen atoms, and structures with $\mathrm{RMSD}_{\text {non-hydrogen }}<0.03 \AA$ were considered to belong to the same conformer. This left 54 unique conformers (i.e., only one duplicate was found). Their structures, total electronic and free energies, relative energies and contributions to the ensemble are available in SI archive "QuantumChemicalCalculations.zip", file “OligomycinA_minima_all.xyz".

\section{Search for transition states of Diels-Alder reactions with benzoquinone}

On the first step, we performed a conformational search for each transition state (TS) type: $\mathbf{T S}_{\text {endo-2a }}, \mathbf{T S}_{\text {exo-2a, }} \mathbf{T S}_{\text {endo-2b, }}, \mathbf{T S}_{\text {exo-2b }}$ - with the diene moiety directed inside and outside of the Oligomycin A cage. Each search employed a series of constraints:

- Torsion angle C2-C56-C55-C17 was constrained to $0^{\circ}$ (Figure S29).

- Distances C17-C133 and C2-C134 were constrained to $2.0 \AA$ (we considered this value to be close to the distance in TS). 


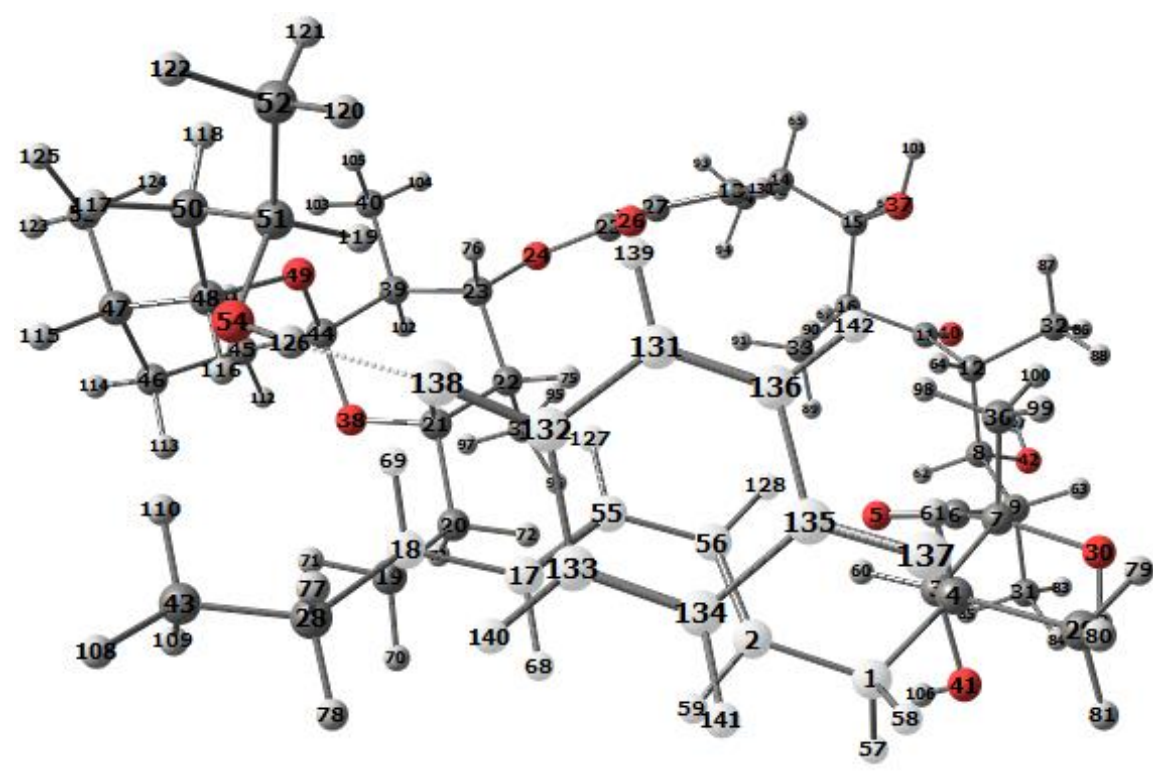

Figure S29. An example TS leading to Oligomycin adduct with benzoquinone. White atoms were treated with $\operatorname{def} 2 S V P$ basis set, the rest - lanl2dz.

Conformational search revealed 294 unique structures (with $\mathrm{RMSD}_{\text {non-hydrogen }}>0.02 \AA$ ) in total, which were then pre-optimized with constrains on C17-C133 and C2-C134 distances; all benzoquinone atoms, as well as all Oligomycin A atoms colored red in Figure S28 were treated with $\operatorname{def} 2 S V P$ basis set, all the rest atoms - with $l a n l 2 d z$. The pre-optimized structures were used as starting guesses for transition states searches at the same level of theory as described above.

All located transition states were compared to each other by means of RMSD of all nonhydrogen atoms, and structures with $\mathrm{RMSD}_{\text {non-hydrogen }}<0.02 \AA$ were considered duplicates, so only one for every TS conformer was retained. This procedure resulted in $\mathbf{8 8}$ unique transition state conformers. Their structures, total electronic and free energies, relative energies and contributions to the reaction flow are available in SI archive "QuantumChemicalCalculations.zip", file "Benzoquinone_TS_all.xyz".

\section{Search for transition states of Diels-Alder reactions with $N$-benzylmaleimide}

On the first step, we performed a conformational search for each transition state (TS) type: $\mathbf{T S}_{\text {endo-2a }}, \mathbf{T S}_{\text {exo-2a, }}, \mathbf{T S}_{\text {endo-2b, }} \mathbf{T S}_{\text {exo-2b}}$ - with the diene moiety directed inside and outside of the Oligomycin A cage. Each search employed a series of constraints:

- Torsion angle C2-C56-C55-C17 was constrained to $0^{\circ}$ (Figure S30).

- Distances C2-C133 and C17-C132 were constrained to be $2.0 \AA$ (we consider this value to be close to the distance in TS). 


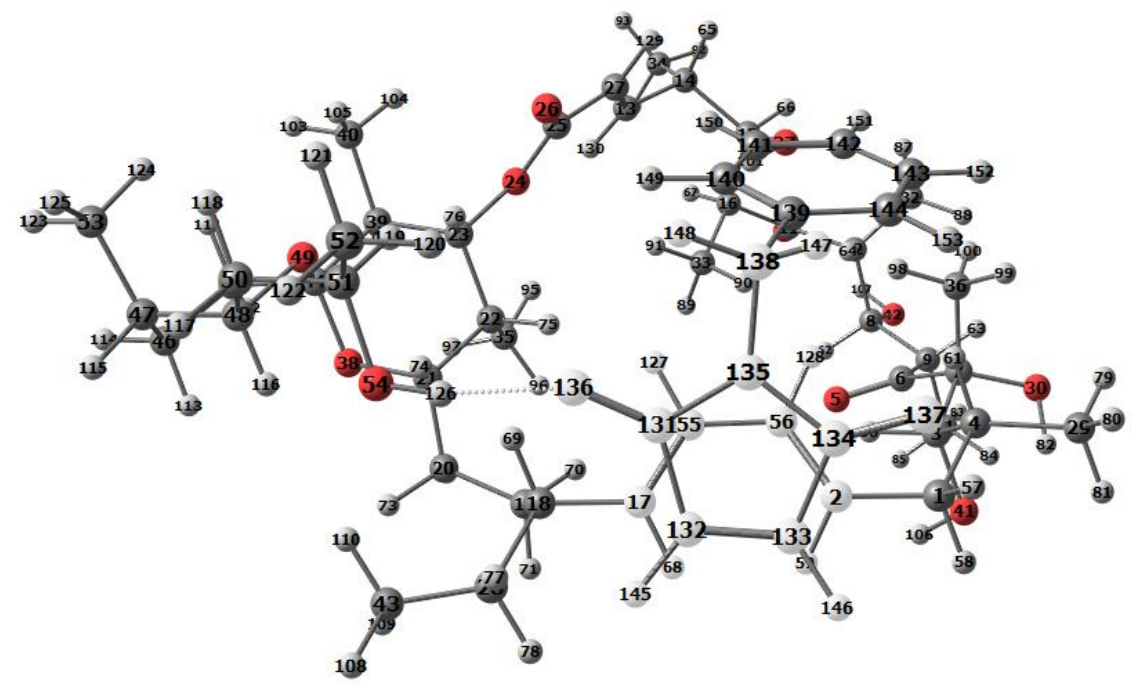

Figure S30. An example TS leading to Oligomycin adduct with N-benzylmaleimide. White atoms correspond to $\operatorname{def} 2 S V P$ basis set, the rest - to $\operatorname{lanl} l 2 d z$.

Conformational search revealed 133 unique structures (with $\mathrm{RMSD}_{\text {non-hydrogen }}>0.2 \AA$ ), in total, which were then pre-optimized with constrains on $\mathrm{C} 17-\mathrm{C} 132$ and $\mathrm{C} 2-\mathrm{C} 133$; all $\mathrm{N}$ benzylmaleimide atoms except for phenyl, as well as all oligomycin A atoms colored red in Figure S28 were treated with def $2 S V P$ basis set, all the rest atoms - with lanl $2 d z$. The preoptimized structures were used as starting guesses for transition states searches at the same level of theory as described above.

All located transition states were compared to each other by means of RMSD of all nonhydrogen atoms, and structures with $\mathrm{RMSD}_{\text {non-hydrogen }}<0.2 \AA$ were considered duplicates, so only one for every TS conformer was retained. This procedure resulted in $\mathbf{5 3}$ unique transition state conformers. Their structures, total electronic and free energies, relative energies and contributions to the reaction flow are available in SI archive "QuantumChemicalCalculations.zip", file "Maleimide_TS_all.xyz".

\section{Calculation of the activation free energies}

To calculate activation free energies, we optimized benzoquinone and $\mathrm{N}$ benzylmaleimide molecules. All benzoquinone atoms and $N$-benzylmaleimide atoms colored white in Figure S30 were treated with def2SVP basis set, the rest $N$-benzylmaleimide atoms with $\operatorname{lanl} 2 d z$.

Activation energies were calculated as differences between the energy of the most stable TS conformation and sum of the energies of the most stable conformation of Oligomycin A and the diene.

Table S1. Quasi-harmonic activation free energies of the studied routes

\begin{tabular}{|c|c|c|}
\hline Product & Lowest-energy transition state & $\begin{array}{c}\text { Activation free energy, } \\
\mathrm{kcal} / \mathrm{mol}\end{array}$ \\
\hline exo-2b & Benzoquinone_TS_conf0 & 13.25 \\
\hline exo-2a & Benzoquinone_TS_conf1 & 15.49 \\
\hline endo-2b & Benzoquinone_TS_conf7 & 19.16 \\
\hline endo-2a & Benzoquinone_TS_conf12 & 19.54 \\
\hline
\end{tabular}




\begin{tabular}{|c|c|c|}
\hline exo-3a & Maleimide_TS_conf1 & 11.15 \\
\hline endo-3b & Maleimide_TS_conf2 & 12.09 \\
\hline endo-3a & Maleimide_TS_conf3 & 15.68 \\
\hline exo-3b & Maleimide_TS_conf21 & 22.20 \\
\hline
\end{tabular}

\section{Conformational search for products of Oligomycin A Diels-Alder reactions}

Because of the conformational lability of products, an ordinary conformational search didn't lead us to conformations agreeing with NMR spectra. For this reason, we resorted to the same constrained conformational searches as for TS, but with constraints provided by NMR: on the known dihedral angles and inter-hydrogen distances (all of them are shown in Figure 3, 4a and $4 \mathrm{~b}$ in the article). The lowest conformers from these constrained conformational searches were used as the start points for unconstrained conformational searches, which results were analyzed.

Structures of the products conformers consistent with NMR data and their total OPLS3 energies are available in SI archive "MolecularMechanicsCalculations.zip".

(1) Mardolcaf, U. V.; Nieto de Castro, C. A.; Santos, F. J. V. Dielectric Constant Measurements of Toluene and Benzene. Fluid Phase Equilibria 1992, 79, 255-264. 